\title{
Exergetic and integrated exergoeconomic assessments of a hybrid solar-biomass organic Rankine cycle cogeneration plant
}

\author{
Joseph Oyekale $^{a, b, c, *}$, Mario Petrollese ${ }^{a}$, Florian Heberle $^{b}$, Dieter Brïggemann $^{b}$, \\ Giorgio Cau ${ }^{a}$ \\ ${ }^{a}$ Department of Mechanical, Chemical and Materials Engineering, University of Cagliari, Via Marengo \\ 2, 09123 Cagliari, Italy \\ ${ }^{b}$ Chair of Engineering Thermodynamics and Transport Processes (LTTT), Center of Energy Technology \\ (ZET), University of Bayreuth, Universitätstraße 30, 95440 Bayreuth, Germany \\ ${ }^{c}$ Department of Mechanical Engineering, Federal University of Petroleum Resources, Effurun, P.M.B. \\ 1221 Effurun, Delta State, Nigeria \\ *Corresponding author: oyekale.oyetola@fupre.edu.ng
}

\begin{abstract}
:
This study is aimed at investigating optimization potentials in a conceptual hybrid solarbiomass organic Rankine cycle (ORC) cogeneration plant, through component-based exergy and exergoeconomic analyses. The ORC is rated at $629 \mathrm{kWe}$, and it is related to a real and operational ORC unit. Exergy balance is established in each system component, from where irreversibility rate in the respective components is obtained. Thus, exergy-based rational efficiency and efficiency defects are computed for each system component. Also, economic performance is assessed at component level, for the entire system, using conventional specific exergy costing (SPECO) approach. The energy quality level of each thermodynamic state is also integrated into SPECO formulations, providing a different way of obtaining unit exergy cost for each stream. This is termed here as integrated exergoeconomic approach. Exergy destruction cost rate, exergoeconomic factor and relative cost difference are used as criteria for exergoeconomic performance evaluation. Furthermore, the level of recoverability of exergy destruction in each of the system components is assessed, in order to identify notable improvement potentials. The evaluation of optimization potentials considers intrinsic irreversibilities in the respective components, which are imposed by the assumptions of systemic and economic constraints, and thus cannot be eliminated. Results showed that system exergetic efficiency amounts to about $11 \%$. Also, cost of producing electricity was obtained as $10.5 \mathrm{c} € / \mathrm{kWh}$ and $12.1 \mathrm{c} € / \mathrm{kWh}$, respectively for conventional and integrated exergoeconomic approach. Furthermore, cost of producing warm water was obtained to be lower by about $56 \%$ in integrated exergoeconomic approach, relative to the conventional approach. For the whole system, adopting integrated exergoeconomic approach led to reduced loss of investment costs by about 1.5 percent points, relative to the conventional approach.
\end{abstract}

\section{Keywords:}


Organic Rankine Cycle, Hybrid solar-biomass energy, Exergy analysis, Exergoeconomic analysis, Energy-level-based exergoeconomic analysis, Avoidable exergy destruction.

\section{Introduction}

According to the New Policies Scenario (NPS) of the International Energy Agency (IEA), world total demand of primary energy had increased by about $39 \%$ between the year 2000 and the year 2017, and about $27 \%$ further increase is projected by the year 2040 [1]. This has placed high premium on the necessity to improve energy supply systems, for sustained satisfaction of human energy needs. Alongside this, the threat posed on the environment by continuous exploitation of conventional fossil fuels for energy production has become apparent, leading to universal campaign for increased commitment to sustainability of the environment. Consequently, huge attention has been shifted to exploitation of renewable energy sources globally, as potential alternative to fossil fuels. However, most renewable energy generation systems are currently associated with low reliability and high costs, amongst other limitations [2]. Thus, efforts targeted at improving their reliability and techno-economic performance are being intensified at the moment. Amongst others, one trending technique with high potentials to achieving these improvements is hybridization of two or more renewable energy resources. In this regard, the authors of this paper have previously proposed and studied a biomass hybridization scheme for existing solar organic Rankine cycle (ORC) systems, based on a real operational plant [3,4]. This study showed that implementing biomass hybridization would truly improve dispatchability and thermo-economic performance of solar-ORC plants. However, it was also obtained that such hybridization scheme would necessitate linking more complex units to the system, with additional degrees of freedom regarding optimal design and operational parameters. Thus, if the advantages intended to be derived from hybridizing renewable energy systems would be fully realized, efforts should be made beyond conceptual design, to investigate available improvement measures necessary for optimal performance of the hybrid plants in practice. In essence, detailed component-based exergoeconomic performance of such systems should be studied, based on the second law of thermodynamics and economic principles.

Premised on this understanding, exergoeconomic assessment is a well-established method to study new or existing renewable energy systems. Moharramian et al. [5] applied two different exergoeconomic procedures to examine performance of a photovoltaic combined cycle with biomass post firing, for production of electrical power and hydrogen. Contributions of each component to thermoeconomic inefficiency of the system were assessed by the applied exergoeconomic methodologies, and potential improvement measures were highlighted. In like manner, Crivellari [6] et al. studied exergoeconomic performance of new concepts for the use of hybrid solar-wind and other renewable energy resources in methanol synthesis processes. Specifically, they designed and compared exergoeconomically, two methanol production schemes involving catalytic hydrogenation of carbon dioxide and direct radical oxidation of methane. They reported that better exergoeconomic performance is obtained in the carbon-dioxide route, having the lowest total cost rate at $1000 \$ / \mathrm{h}$. Also, Anvari et al. [7] investigated viability of a proposed configuration of hybrid solar-biomass power plant, using exergoeconomic and environmental methods. The authors reported that adding solar unit to biomass system increased power production by about $30 \%$, and it equally improved economic and environmental performance of the plant. Similarly, Calise et al. [8] proposed a hybrid solar-geothermal polygeneration plant for production of electricity, hot water, chilled water as well as desalted water. Based on exergetic and exergoeconomic analysis of the plant, detailed hourly, daily, weekly and annual thermodynamic and economic performance of each component were reported, and areas requiring improvements in the plant were identified. They reported particularly that exergoeconomic costs vary for electricity, chilled water, cooling water and desalinated water in the range of $0.1475-0.1722 € / \mathrm{kWh}, 0.1863-$ $0.1888 € / \mathrm{kWh}$ ex, $0.01612-0.01702 € / \mathrm{kWh}$ ex , and 0.5695-0.6023 $€ / \mathrm{kWh}$ ex, respectively. In addition, Sadi and Arabkoohsar [9] employed exergoeconomic analysis to investigate sources of 
irreversibilities and economic inefficiencies in a power plant driven by hybrid solar and waste-heat sources. Based on their findings, recommendations were made on possible measures that could improve exergoeconomic performance of the plant, reporting that about $32 \%$ decrease in unit exergy cost of producing electrical energy was achievable. Rahnama et al. [10] employed exergoeconomic and exergoenvironmental methods to develop solar maps for Iranian climatic conditions, reporting that it enhances location and accessibility of installed photovoltaic systems in the country. Kheshtkar and Khani [11] optimized a hybrid solar-wind polygeneration plant, based on exergoeconomic principles. They reported that the operating cost of the hybrid plant obtained originally as $8.45 \$ /$ hour could be reduced by about $23 \%$, post optimization. Furthermore, Elbar et al. [12] proposed integration of solar still to photovoltaic system, and applied energy, exergy, exergoeconomic and exergoenvironmental methodologies to examine the impacts of such integration, relative to conventional solar still energy plants. They reported that integrating solar still to photovoltaic system would enhance exergoeconomic performance of conventional systems. Habibollahzade et al. [13] carried out exergoeconomic assessment and multi-objective optimization of a solar chimney integrated with waste-to-energy plant. The integration was done in form of a retrofit to an existing waste-to-energy plant in Iran, and authors reported that, after optimization procedures, exergetic efficiency and cost rate of the integrated plant was obtained as $7.6 \%$ and 406.8 \$hour, respectively. Baghernejad et al. [14] also applied exergoeconomic method to compare three trigeneration systems based on solid oxide fuel cell, biomass and solar sources of energy. They reported that, although lowest exergy costs were obtained for the biomass-trigeneration system at 68.2 cents $\$ / \mathrm{kWh}$, it was found to be environmentally inefficient, recording the highest $\mathrm{CO}_{2}$ emissions relative to other systems.

All the above-cited studies on exergoeconomic analysis of renewable energy systems as well as several others too numerous to mention here have upheld fuel-product principle proposed in conventional specific exergy costing (SPECO) exergoeconomic method [15]. This principle assumes that unit cost of fuel exergy entering a system based on a given working substance is the same as the unit cost of product exergy leaving the system for the same working substance. This is without making any reference to the energy content of the inlet (fuel) and exit (product) streams interfacing the system unit. But, in fact, it is opined that this assumption is not totally compliant with conventional principles of energy economics [16]. Based on these economic principles, one could argue that unit exergy of each stream should have some correlations with its energy quality level; a parameter that indicates how much of the stream energy content could be converted to useful work. In this regard, methodology developed in [17] for estimating energy quality level of a thermodynamic state had been integrated into cost formation process of SPECO [18], by assuming linear correlation between stream energy quality and its unit exergy cost. Nevertheless, this modified methodology, termed integrated exergoeconomic approach in this paper has not been quite embraced as yet in literature, perhaps due to lack of convincing studies to validate its advantages relative to the well-established conventional approach. Thus, it is essential to further investigate the merits of the exergoeconomic approach that integrates energy quality level to cost analysis over the conventional one, through increased application and comparison of the two methods in practical energy systems.

Sequel to the foregoing, detailed exergy, conventional and integrated exergoeconomic analyses of a novel hybrid solar-biomass organic Rankine cycle (ORC) power plant have been carried out in this paper. The hybrid plant is strongly related to a real solar-ORC plant, which currently runs at Ottana, Italy [4]. As aforementioned, the different sub-sections of the plant had been studied previously in great detail, both at design and off-design conditions. Furthermore, the ORC behaviour during simulation had been validated by data obtained from the operation of the live plant. The aim in this paper is to investigate optimization potentials in the hybrid plant, through comprehensive exergy and exergoeconomic assessment. The main contribution of this paper is in the integration of energylevel concept to cost formation process in exergoeconomic analysis of the plant. Considering that the hybrid plant is based on a real operational system, the findings of this study would provide decisive information as to whether or not energy quality levels of thermodynamic streams should be 
considered in exergoeconomic analysis. In addition, the comprehensive exergy-based analyses reported in this paper would not only enable improvement of the existing real plant at Ottana, but would also give valuable insights for better future design of similar novel hybrid plants around the globe. Moreover, emanating from what is replete in literature [19,20], an enhanced methodology [21] has also been included, to examine the actual parts of destroyed exergy in each component that could be avoided by optimization efforts. The tangential objectives of the study are:

- Quantification of exergy rate in each thermodynamic state, and irreversibility in each component of the hybrid plant, as well as assessment of overall exergetic performance of the plant;

- Estimation of exergy cost rates for all thermodynamic states and components of the plant, as well as assessment of exergoeconomic performance of components and the whole plant;

- Comparative analysis of the impacts that integrating energy quality levels of streams to cost formation process would have on exergoeconomic performance of the hybrid plant;

- Determination of avoidable and unavoidable irreversibility in each component, in order to assess components requiring utmost thermodynamic improvement efforts.

\section{Methodology}

\subsection{System description}

The scheme of the hybrid Concentrated Solar Power (CSP)-biomass Organic Rankine Cycle (ORC) plant studied in this paper is illustrated in Figure 1 [3]. As shown, the ORC is jointly fed by thermal power from solar field and biomass furnace. The solar field consists of Linear Fresnel Collectors (LFC), with thermal oil as heat transfer fluid (HTF). A two-tank Thermal Energy Storage (TES) system is integrated with the solar field. TES cold tank stores HTF to be heated by useful energy collected from the sun, after which the HTF is stored in the TES hot tank, from where the ORC is fed. The biomass section consists of a control-based modular boiler, with the combustion zone dominated by convection heat transfer processes and separated from HTF heater. Hot combustion flue gases exiting the furnace heater preheat the inlet air into the combustion chamber, before escaping to the atmosphere. A three-way valve upstream of the ORC regulates the flow of HTF from solar field and biomass furnace. Similarly, another three-way valve downstream of the ORC controls the distribution of HTF into the TES cold tank and cold side of the furnace heater. The same thermal fluid is considered for both the solar field and biomass furnace heater, as well as TES medium. The ORC is of recuperative subcritical configuration, and water is considered as condensation medium. Design characteristics of the hybrid plant are highlighted in Table 1. 


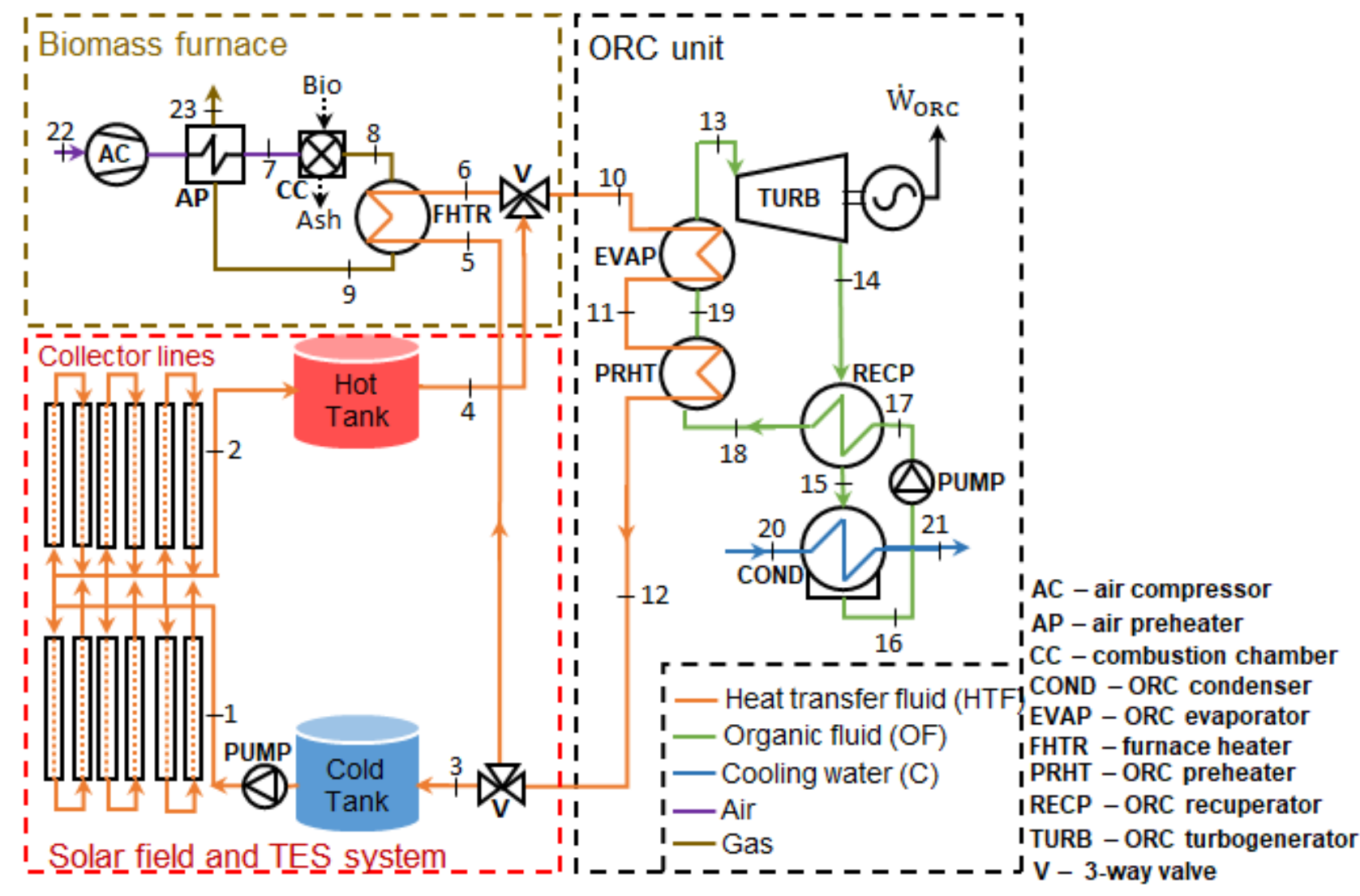

176 Figure 1-Conceptual scheme of the hybrid CSP-biomass ORC plant [3]

Table 1 - Design characteristics of hybrid CSP-biomass ORC plant

\begin{tabular}{|c|c|c|c|}
\hline \multicolumn{2}{|l|}{ Solar Field } & \multicolumn{2}{|l|}{ ORC unit } \\
\hline Collector focal length & $4.97 \mathrm{~m}$ & Working fluid & $\mathrm{C}_{6} \mathrm{H}_{18} \mathrm{OSi}_{2}$ \\
\hline Collector length & $99.45 \mathrm{~m}$ & Heat sink & Water \\
\hline Net Effective area $\left(\mathrm{A}_{\mathrm{sf}}\right)$ & $8400 \mathrm{~m}^{2}$ & Net electrical power & $629 \mathrm{~kW}$ \\
\hline Optical efficiency $\left(\eta_{\text {opt }}\right)$ & $64 \%$ & Design thermal power input & $3178 \mathrm{~kW}$ \\
\hline Mean ambient temperature & $25^{\circ} \mathrm{C}$ & Design HTF mass flow rate & $11.05 \mathrm{~kg} / \mathrm{s}$ \\
\hline Mean ambient pressure & $1 \mathrm{~atm}$ & Pump isentropic efficiency & $80 \%$ \\
\hline Design inlet temperature & $165^{\circ} \mathrm{C}$ & Pump motor efficiency & $98 \%$ \\
\hline \multirow[t]{2}{*}{ Design outlet temperature } & $275^{\circ} \mathrm{C}$ & Turbine isentropic efficiency & $85 \%$ \\
\hline & & Electromechanical efficiency & $92 \%$ \\
\hline TES system & & \multicolumn{2}{|l|}{ Biomass Combustion } \\
\hline \multirow{9}{*}{$\begin{array}{l}\text { Storage capacity } \\
\text { Tank useful volume } \\
\text { Aspect ratio } \\
\text { Ambient wind speed }\left(v_{a}\right) \\
\text { Insulation thickness } \\
\text { Insulation thermal } \\
\text { conductivity }\end{array}$} & 15.4 MWh & Furnace thermal duty & $1430 \mathrm{~kW}$ \\
\hline & $330 \mathrm{~m}^{3}$ & \multirow{3}{*}{$\begin{array}{l}\text { Fuel composition (dry basis, } \\
\% \text { by weight) }\end{array}$} & $48.3 \% \mathrm{C}, 5.9 \% \mathrm{H}$, \\
\hline & 0.32 & & $0.1 \% \mathrm{~N}_{2}, 38.5 \%$ \\
\hline & $3 \mathrm{~m} / \mathrm{s}$ & & $\mathrm{O}_{2}, 7.2 \%$ Ash \\
\hline & $0.5 \mathrm{~m}$ & LHV (dry basis) & $16.3 \mathrm{MJ} / \mathrm{kg}$ \\
\hline & & Moisture content & $20 \%$ \\
\hline & $0.16 \mathrm{~W} / \mathrm{m}$ & Stoichiometric air-fuel ratio & 5 \\
\hline & & Excess air & $150 \%$ \\
\hline & & Combustion efficiency & $99 \%$ \\
\hline
\end{tabular}

\subsection{Thermodynamic analysis}

179 Mass balance and energy balance of each system component are established in this study, prior to the intended component-based exergy analysis. The classical exergy rate balance equation was implemented at steady state for each component, as follows [22]: 


$$
\sum \dot{\mathrm{m}}_{\mathrm{i}} \mathrm{e}_{\mathrm{i}}+\dot{\mathrm{Q}}\left(1-\frac{T_{a}}{T_{c}}\right)=\sum \dot{\mathrm{m}}_{\mathrm{o}} \mathrm{e}_{\mathrm{o}}+\dot{\mathrm{W}}+\dot{\mathrm{I}}
$$

182

183

184

185

186

187

188

189

190

191

192

194

195

196

197

198

199

200

201

202

where $\dot{m}$ is mass flow rate of the stream substance, $h$ is the specific enthalpy, $\dot{Q}$ is heat flow through component boundary, $T_{a}$ is the temperature of the environment, $T_{c}$ is the temperature at component boundary, at which heat is exchanged with the environment, $e$ is the specific exergy of the stream, $\dot{W}$ is work rate of the component, and $\dot{I}$ is the rate of exergy destroyed in the component (irreversibility). Subscripts $i$ and $o$ represent inlet and exit to and from the component, respectively. Only the physical $\left(e_{p h}\right)$ and chemical $\left(e_{c h}\right)$ components of specific exergy were considered, the sum of which gives $e$ for each stream. However, in components without interactions with the environment, the chemical exergy cancels out between two state points with the same working substance, such that only the physical exergy defines the total specific exergy of such streams [23]. The fundamental equation for estimating physical exergy is given as:

$$
e_{p h}=\left(h-h_{a}\right)-T_{a}\left(s-s_{a}\right)
$$

Where $h$ and $s$ are the specific enthalpy and entropy of the stream while $h_{a}$ and $s_{a}$ are the specific enthalpy and specific entropy of the environment, respectively. Specific chemical exergy of stream depends on the stream composition, as well as reference state of the environment. In particular, specific chemical exergy $\left(e_{c h}\right)$ of flue gases was computed as follows:

$$
e_{c h}=\left(\sum_{i} x_{i} \hat{\mathrm{r}}_{i}+\mathrm{R} T_{a} \sum_{i} x_{i} \ln x_{i}\right) / m m
$$

where $x_{i}$ and $\hat{r}_{i}$ represent molar fraction and reference standard exergy of each component of the gaseous streams (taken in accordance with [22]), respectively; $R$ is the universal gas constant, and $\mathrm{mm}$ is the average molar mass of the chemical stream. Also, specific chemical exergy of biomass fuel $\left(e_{c h, b}\right)$ was computed as follows [23]:

$$
e_{c h, b}=\beta \cdot L H V
$$

where $\beta$ is an index quantifying the chemical exergy in organic fuels, and $L H V$ is the lower heating value of the biomass fuel. The expressions adopted for $\beta$ is as follows [23]:

$$
\beta=\frac{1.044+0.016 \frac{H}{C}-0.34493 \frac{O}{C}\left(1+0.0531 \frac{H}{C}\right)}{1-0.4124 \frac{O}{C}}
$$

giving a value of 1.141 by assuming the composition of the considered biomass.

\subsubsection{Solar field}

The fuel exergy of the solar field is exergy associated with the solar radiation $\left(\dot{E}_{\mathrm{s}}\right)$, which is defined as [24]:

$$
\dot{E}_{S}=D N I \cdot A_{s f}\left[1-\frac{4}{3} \frac{T_{a}}{T_{s}}+\frac{1}{3} \frac{T_{a}^{4}}{T_{s}^{4}}\right]
$$

where $D N I$ is the direct normal irradiation, $A_{s f}$ is the solar field collecting area and $T_{s}$ is the sun temperature (imposed equal to $5770 \mathrm{~K}$ ). The exergy content of the solar radiation is strongly devalued by irreversibility (related to the temperature difference between the sun and the receiver) and thermal and optical losses $\left(\dot{Q}_{l o s s, s f}\right)$. The latter are calculated as: 


$$
\dot{Q}_{l o s s, s f}=\left[D N I\left(1-\eta_{o p t}\right)+\left(a_{1}\left(T_{a v}-T_{a}\right)+a_{2}\left(T_{a v}-T_{a}\right)^{2}+\dot{q}_{p l}\right)\right] \cdot A_{s f}
$$

where $\eta_{o p t}$ is the total optical efficiency, $T_{a v}$ is the average solar field temperature, $a_{1}$ and $a_{2}$ are coefficients related to receiver thermal losses (imposed equal to $0.056 \mathrm{~W} / \mathrm{m}^{2} \mathrm{~K}$ and $0.213 \cdot 10^{-3}$ $\mathrm{W} / \mathrm{m}^{2} \mathrm{~K}^{2}$ respectively, according to [25]) and $\dot{q}_{p l}$ represents the piping thermal losses (set equal to 5 $\mathrm{W} / \mathrm{m}^{2}$ ). Average DNI of $501 \mathrm{~W} / \mathrm{m}^{2}$ was used for analysis in this paper, determined based on the quantity of solar thermal power required to preserve nominal design features of the ORC plant post biomass retrofit, as reported in Table 1.

\subsubsection{TES system}

Due to imperfect insulation in the thermal energy storage (TES) tanks, the temperature of storage fluid drops over time, resulting in thermal losses. This temperature drop was considered in this study, as follows [26]:

$$
\frac{T(t)-T_{a}}{T_{i}-T_{a}}=e^{-\left(U \cdot A_{T E S} \cdot t\right) /\left(\rho_{H T F} \cdot c_{H T F} \cdot V_{H T F}\right)}
$$

where $T, \rho_{H T F}, V_{H T F}$, and $c_{H T F}$ are the temperature, density, volume and specific heat capacity of heat transfer fluid, respectively; $A_{T E S}$ is the heat transfer area of storage thermal oil; $t$ is time; and $U$ is the overall heat transfer coefficient, obtained as follows [27]:

$$
U=\frac{d_{\text {ins }}}{k_{\text {ins }}}+\frac{1}{\alpha_{\text {air }}}
$$

where $d_{\text {ins }}(0.5 \mathrm{~m})$ and $k_{\text {ins }}\left(0.16 \mathrm{~W} / \mathrm{m}^{2} \mathrm{~K}\right)$ are respectively the thickness and thermal conductivity of the insulation material. The convection heat transfer coefficient of air $\left(\alpha_{\text {air }}\right)$ was estimated as a function of the wind speed $\left(v_{a}\right)$, as follows:

$$
\alpha_{\text {air }}=10.45-v_{a}+10 \sqrt{v_{a}}
$$

Climatic conditions of Ottana $\left(40^{\circ} 25^{\prime} 00^{\prime \prime} \mathrm{N}, 9^{\circ} 00^{\prime} 00^{\prime \prime} \mathrm{E}\right)$ were used for investigation, as obtained from Meteonorm Software [28].

\subsubsection{ORC unit}

Zero-dimensional models were developed for each component of the ORC, with reference to mass, energy and exergy balance equations, as well as the design characteristics highlighted in Table 1. Inlet and exit temperatures of thermal source HTF were fixed at $275{ }^{\circ} \mathrm{C}$ and $165{ }^{\circ} \mathrm{C}$ respectively, in accordance with the existing real ORC plant. Thermodynamic calculations were performed in Matlab environment, while stream properties were computed with CoolProp [29]. For ORC working fluid $(M M)$, equation of states reported by Thol et al. [30] was adopted for computations. For selected high temperature heat transfer fluids (Therminol and Dowtherm fluids, for instance), CoolProp employed commercial datasheets to compute heat transfer coefficients [29], and the same approach was employed for obtaining specific heat properties of the source heat transfer fluid (in particular, Therminol 66 was selected in this study).

\subsubsection{Exergetic performance parameters}

In order to examine the exergetic performance of each system component $k$, rational efficiency $\left(\varepsilon_{k}\right)$, efficiency defect $\left(\delta_{k}\right)$ and relative irreversibilities $\left(R I_{k}\right)$ were computed as follows:

$$
\varepsilon_{k}=\frac{\dot{E}_{o, k}}{\dot{E}_{i, k}}
$$




$$
\begin{gathered}
\delta_{k}=\frac{\dot{I_{k}}}{\dot{E}_{i, k}} \\
R I_{k}=\frac{\dot{I}_{k}}{\sum \dot{I}_{k}}
\end{gathered}
$$

where $\dot{E}_{o, k}$ and $\dot{E}_{i, k}$ are respectively the product and fuel exergy of the k-th component (Table 2 reports the expressions for each component, and Figure 1 reports the stream labels), while $\dot{I}_{k}$ is the corresponding destroyed exergy. For solar field and combustion chamber, where thermal losses to the ambient were considered, the efficiency defect due to losses is the ratio of lost exergy to component fuel.

For the system as a whole, rational efficiency is the ratio of overall product exergy to fuel exergy. The main fuels are the actual solar exergy received by the collectors $\left(\dot{E}_{s}\right)$, as well as biomass exergy $\left(\dot{m}_{b} e_{c h, b}\right)$. The main products from the system are the net turbine work and warm water obtained at condenser exit.

Table 2. Component fuel and product exergy

\begin{tabular}{cccc}
\hline Component (abbreviation) & Fuel exergy & Product exergy & 252 \\
\hline Solar field (SF) & $\dot{E}_{S}$ & $\dot{m}_{2} e_{2}-\dot{m}_{1} e_{1}$ & 253 \\
Hot tank (HT) & $\dot{m}_{2} e_{2}$ & $\dot{m}_{4} e_{4}$ & 254 \\
Cold tank (CT) & $\dot{m}_{3} e_{3}$ & $\dot{m}_{1} e_{1}$ & 255 \\
Air preheater (AP) & $\dot{m}_{9} e_{9}-\dot{m}_{23} e_{23}$ & $\dot{m}_{7} e_{7}-\dot{m}_{22} e_{22}$ & 256 \\
Combustion chamber (CC) & $\dot{m}_{b} e_{c h, b}+\dot{m}_{7} e_{7}$ & $\dot{m}_{8} e_{8}$ & 257 \\
Furnace heater (FH) & $\dot{m}_{8} e_{8}-\dot{m}_{9} e_{9}$ & $\dot{m}_{6} e_{6}-\dot{m}_{5} e_{5}$ & 258 \\
ORC preheater (PRHT) & $\dot{m}_{11} e_{11}-\dot{m}_{12} e_{12}$ & $\dot{m}_{19} e_{19}-\dot{m}_{18} e_{18}$ & 259 \\
Evaporator (EVAP) & $\dot{m}_{10} e_{10}-\dot{m}_{11} e_{11}$ & $\dot{m}_{13} e_{13}-\dot{m}_{19} e_{19}$ & 261 \\
Recuperator (RECP) & $\dot{m}_{14} e_{14}-\dot{m}_{15} e_{15}$ & $\dot{m}_{18} e_{18}-\dot{m}_{17} e_{17}$ & 262 \\
Condenser (COND) & $\dot{m}_{15} e_{15}-\dot{m}_{16} e_{16}$ & $\dot{m}_{21} e_{21}-\dot{m}_{20} e_{20}$ & 263 \\
Pump (PUMP) & $\dot{W}_{P U M P}$ & $\dot{m}_{17} e_{17}-\dot{m}_{16} e_{16}$ & 264 \\
Turbine (TURB) & $\dot{m}_{13} e_{13}-\dot{m}_{14} e_{14}$ & $\dot{W}_{T U R B}$ & 265 \\
Valve 1 (V1) & $\dot{m}_{4} e_{4}+\dot{m}_{6} e_{6}$ & $\dot{m}_{10} e_{10}$ & 266 \\
Valve 2(V2) & $\dot{m}_{12} e_{12}$ & $\dot{m}_{3} e_{3}+\dot{m}_{5} e_{5}$ & 268 \\
\hline
\end{tabular}

\subsection{Exergoeconomic analysis}

Exergoeconomic analysis of energy systems is a powerful tool, which combines exergy-analysis and cost-analysis principles in its formulation. It is aimed at providing useful insights into the costs of useful and destroyed exergy in each system component, thereby providing vital information on components with high potentials for optimization. In this study, the Specific Exergy Costing (SPECO) methodology was adopted for implementation, in two different approaches. The first one is the conventional approach as proposed originally by Lazzaretto and Tsatsaronis [15]. This approach assumes that, for the same working substance entering and leaving a component, unit cost of exergy is the same at inlet and exit streams, regardless of the quality of energy content of the streams. The second approach implemented in this study integrates energy quality of streams to cost 
formation process in SPECO analysis, and it is termed integrated exergoeconomic approach in this paper. The actual formulations of the two exergoeconomic approaches are summarized below.

\subsubsection{Conventional exergoeconomic approach}

283

284

As a prelude to applying SPECO for conventional exergoeconomic analysis, the exergy of each stream and destroyed exergy in each component should be quantified from exergy analysis. Afterwards, the exergoeconomic analysis consists of the following essential steps: (1) the desired exergy output from respective components (product exergy) and net exergy expended in each component (fuel exergy) should be defined; (2) cost rate balance equations should be defined for each component, generally given as follows [15]:

$$
\sum c \dot{E}_{i}+c_{q} \dot{E}_{q}+\dot{Z}=\sum c \dot{E}_{o}+c_{w} \dot{W}
$$

with $c, \dot{E}$ and $\dot{E}_{q}$ representing stream cost per unit exergy, stream total exergy rate, and exergy rate due to heat transfer with a component, respectively; $c_{q}$ and $c_{w}$ are cost per unit exergy of heat and work exchange with a component, respectively; and $\dot{Z}$ is the cost rate due to investment, operation and maintenance of a component, calculated as:

$$
\dot{Z}=Z \cdot \frac{1}{H_{A}} \cdot \frac{i n t(1+i n t)^{N}}{(1+i n t)^{N}-1} \cdot(1+M F)
$$

where $Z$ is the purchase cost of a component, $H_{A}$ is the annual equivalent working hours of the plant (taken as 6000 hours in this study), $M F$ is the maintenance factor (assumed equal to $6 \%$ ), int is interest rate ( $7 \%$ here) and $N$ is the plant life time (taken as 25 years). The purchase costs of solar field and TES were taken as $160 € / \mathrm{m}^{2}$ and $45 € / \mathrm{kWh}$, respectively [31]. For ORC and biomass components, purchase costs were obtained from Turton et al. [32,33]. Shell and tube configuration was assumed for heat exchangers, and using effectiveness-NTU approach, heat exchange surface areas were obtained as $28.2 \mathrm{~m}^{2}, 54.7 \mathrm{~m}^{2}, 58.6 \mathrm{~m}^{2}, 106.4 \mathrm{~m}^{2}, 440 \mathrm{~m}^{2}$ and $415 \mathrm{~m}^{2}$ for air preheater, furnace heater, ORC preheater, condenser, evaporator and recuperator, respectively. Costs associated with engineering, procurement and construction (EPC) as well as taxes were factored into $Z$, at $11 \%$. Based on fuel-product principles of SPECO [15], auxiliary equations were defined, to facilitate simultaneous solution of the cost rate balance equations, from where values for $c$ for all streams were obtained.

\subsubsection{Integrated exergoeconomic approach}

As aforementioned, conventional SPECO methodology as proposed and as applied widely today follows fuel-product principle that excludes quality of stream energy in cost formation process. Oftentimes, this gives erroneous information regarding the cost required to utilize waste heat meant to be rejected to the surrounding, for generation of another product in form of cogeneration or polygeneration [34]. In an attempt to ameliorate this effect, the energy level methodology developed in [17] had been integrated into cost formation process of SPECO [18]. This was achieved by modifying fuel-product principle used in formulating auxiliary equations, based on the assertion that unit exergy cost of each stream should be linearly proportional to its energy quality level. Specifically, for the same working substance entering a component from stream $i$ and leaving through stream $o$, the fuel-product cost principle based on the integrated exergoeconomic approach is expressed as follows:

$$
\frac{c_{i}}{G_{i}}=\frac{c_{o}}{G_{o}}
$$




$$
G=1-T_{a}\left(\frac{d S}{d H}\right)=\left|1-\frac{T_{a}}{T}\right|
$$

where $d S$ and $d H$ are entropy change and enthalpy change, respectively. Based on this concept, all the auxiliary equations needed to obtain unit exergy cost for each stream were re-formulated, which is the only major difference between integrated and conventional exergoeconomic approaches implemented in this study. In addition, the unit cost of loss exergy of flue gas is set as zero under this approach [35]. Although the best way to treat cost of loss exergy in exergoeconomic analysis is an open discourse, it is adequate here to assign zero cost to exergy of the flue gas exiting the system for inclusion in costs of other components, since it could otherwise be recovered for further use in the system.

\subsubsection{Exergoeconomic performance criteria}

For the two approaches, the exergoeconomic performance of each component was assessed, using the cost rate of destroyed exergy $\left(\dot{C}_{D}\right)$, exergoeconomic factor $(f)$ as well as relative cost difference $(r)$, defined as follows [35]:

$$
\dot{C}_{D}=c_{f} \cdot \dot{I}
$$

$$
\begin{gathered}
f=\frac{\dot{\mathrm{Z}}}{\dot{\mathrm{Z}}+\dot{C}_{D}+\dot{C}_{L}} \\
r=\frac{c_{p}-c_{f}}{c_{f}}
\end{gathered}
$$

where $c_{f}, c_{p}$ and $\dot{C}_{L}$ represent cost per unit of fuel exergy (ratio of cost rate of fuel to fuel exergy, $€ / \mathrm{kWh}$ ), cost per unit of product exergy (ratio of cost rate of product to product exergy, $€ / \mathrm{kWh}$ ) and cost rate of lost exergy $(€ / \mathrm{h})$, respectively. Furthermore, huge exergy is expected to be lost due to inability of solar collectors to fully absorb transmitted solar energy. These losses are somewhat natural and unavoidable, due to atmospheric radiation processes, as well as diffusion on impinging the focused solar collectors. In essence, it would be inappropriate to insinuate that all losses in such unit are due to decrease in exergy transfer as a result of inefficiency of the unit, and distinctions between lost and destroyed exergy have thus been made in this regard. However, since solar energy is treated as free fuel (zero cost), it is acceptable to disregard cost due to lost exergy for this unit. The cost of exergy lost to diffusion of solar irradiation was thus taken as zero.

For the whole system, $f$ and unit cost of turbine work have been used as main evaluation criteria. While the unit cost of turbine work is obtainable directly from SPECO, the definition of $f$ given in eq. (19) had been applied, with $\dot{\mathrm{Z}}, \dot{C}_{D}$ and $\dot{C}_{L}$ taken as the sum for all system components. For each

\begin{tabular}{|c|c|c|c|}
\hline Component (abbreviation) & Cost rate balance equation & $\begin{array}{l}\text { Auxiliary } \\
\text { equation } \\
\text { (conventional) }\end{array}$ & $\begin{array}{l}\text { Auxiliary } \\
\text { equation } \\
\text { (integrated) }\end{array}$ \\
\hline
\end{tabular}
component, expressions for cost rate balance as well as auxiliary equations for conventional and integrated exergoeconomic approaches are highlighted in Table 3.

Table 3 - Cost rate balance and auxiliary equations for conventional and integrated approaches

Solar field (SF)

$\dot{C}_{1}+\dot{Z}_{S F}=\dot{C}_{2}$

$c_{s}=0$

$c_{s}=0$ 
Hot tank (HT)

$$
\dot{C}_{2}+\dot{Z}_{H T}=\dot{C}_{4}
$$

Cold tank (CT)

Air preheater (AP)

$\dot{C}_{3}+\dot{Z}_{C T}=\dot{C}_{1}$

Combustion chamber (CC)

$\dot{C}_{22}+\dot{C}_{9}+\dot{Z}_{A P}=\dot{C}_{23}+\dot{C}_{7}$

$c_{22}=0 ; c_{9}=c_{23}$

$c_{22}=0 ; c_{23}=0$

Furnace heater (FH)

$\dot{C}_{7}+\dot{C}_{b}+\dot{Z}_{C C}=\dot{C}_{8}$

$c_{b}=1.1 \frac{\mathrm{c} €}{\mathrm{kWh}}$

$c_{b}=1.1 \frac{\mathrm{c} €}{\mathrm{kWh}}$

Furnace heater (FH)

$\dot{C}_{8}+\dot{C}_{5}+\dot{Z}_{F H}=\dot{C}_{9}+\dot{C}_{6}$

$c_{8}=c_{9}$

$\frac{c_{8}}{G_{8}}=\frac{c_{9}}{G_{9}}$

ORC preheater (PRHT)

$\dot{C}_{11}+\dot{C}_{18}+\dot{Z}_{P R H T}=\dot{C}_{19}+\dot{C}_{12} \quad c_{11}=c_{12}$

$\frac{c_{11}}{G_{11}}=\frac{c_{12}}{G_{12}}$

Evaporator (EVAP)

$\dot{C}_{10}+\dot{C}_{19}+\dot{Z}_{E V A P}=\dot{C}_{11}+\dot{C}_{13} \quad c_{10}=c_{11}$

$\frac{c_{10}}{G_{10}}=\frac{c_{11}}{G_{11}}$

Recuperator (RECP)

$\dot{C}_{14}+\dot{C}_{17}+\dot{Z}_{R E C P}=\dot{C}_{15}+\dot{C}_{18} \quad c_{14}=c_{15}$

$\frac{c_{14}}{G_{14}}=\frac{c_{15}}{G_{15}}$

Condenser (COND)

$\dot{C}_{15}+\dot{C}_{20}+\dot{Z}_{C O N D}=\dot{C}_{16}+\dot{C}_{21} \quad c_{20}=0 ; c_{15}=c_{16}$

$c_{20}=0 ; \frac{c_{15}}{G_{15}}=\frac{c_{16}}{G_{16}}$

Pump (PUMP)

$\dot{C}_{16}+\dot{C}_{w, p}+\dot{Z}_{P U M P}=\dot{C}_{17}$

$c_{w, p}=c_{w, T}$

$c_{w, p}=c_{w, T}$

Turbine (TURB)

$\dot{C}_{13}+\dot{Z}_{T U R B}=\dot{C}_{w, T}+\dot{C}_{14}$

$c_{13}=c_{14}$

$\frac{c_{13}}{G_{13}}=\frac{c_{14}}{G_{14}}$

Valve 1 (V1)

$\dot{C}_{4}+\dot{C}_{6}+\dot{Z}_{V 1}=\dot{C}_{10}$

Valve 2 (V2)

$\dot{C}_{12}+\dot{Z}_{V 2}=\dot{C}_{3}+\dot{C}_{5}$

$c_{12}=c_{3}=c_{5}$

$c_{12}=c_{3}=c_{5}$

\subsection{Enhanced exergy analysis}

The assessment of optimization potentials in each component using exergy analysis quantifies the rate of exergy destruction in each system component, with the erroneous assumption that all these irreversibilities could be recovered. In actual fact, some irreversibilities are intrinsic in energy system components, due to systemic and economic constraints imposed by thermodynamic laws. In essence, this unavoidable exergy destruction should be regarded, when applying exergy analysis for assessing improvement potentials in energy systems. To estimate unavoidable part of destroyed exergy in a component $k$, the best possible performance characteristics of component $k$ are imposed during exergy analysis, while other system components remain at their real states [21]. The ratio of destroyed exergy to product exergy of component $k$ obtained under this circumstance, $\left(\frac{\dot{\mathrm{E}}_{D}}{\dot{\mathrm{E}}_{P}}\right)_{\boldsymbol{k}}^{U N}$, is then used for estimating unavoidable part of exergy destruction in component $k, \dot{E}_{D, k}^{U N}$, as follows [21]:

$$
\dot{E}_{D, k}^{U N}=\dot{E}_{o, k} \times\left(\frac{\dot{\mathrm{E}}_{D}}{\dot{\mathrm{E}}_{P}}\right)_{k}^{U N}
$$

This leaves the part of destroyed exergy in $k$ that could be eliminated by optimization efforts (avoidable part of destroyed exergy, $\dot{E}_{D, k}^{A V}$ ) as:

$$
\dot{E}_{D, k}^{A V}=\dot{I}_{k}-\dot{E}_{D, k}^{U N}
$$

The enhanced exergy efficiency $\left(\varepsilon^{*}\right)$ under this condition was estimated by:

$$
\varepsilon^{*}=\frac{\dot{E}_{o, k}}{\dot{E}_{i, k}-\dot{E}_{D, k}^{U N}}
$$


Assumptions for the best performance characteristics applied for obtaining unavoidable irreversibilities in this study are based both on empirical judgement and literature, as highlighted in Table 4.

366 Table 4-Assumptions for unavoidable conditions of system components

\begin{tabular}{llll}
\hline Component & Unavoidable conditions & Component & Unavoidable conditions \\
\hline Solar field & $\left(\frac{\dot{\mathrm{E}}_{D}}{\dot{\mathrm{E}}_{P}}\right)_{s f}^{U N}=0.7638[36]$ & Furnace heater & $\Delta T_{\min }=3 \mathrm{~K}$ \\
Hot tank & Perfect insulation & ORC preheater & $\Delta T_{\min }=3 \mathrm{~K}$ \\
Cold tank & Perfect insulation & Evaporator & $\Delta T_{\min }=5 \mathrm{~K}$ \\
Air preheater & $\Delta T_{\min }=12 \mathrm{~K}$ & Recuperator & effectiveness $=0.9$ \\
& Adiabatic condition; air- & Condenser & $\Delta T_{\text {min }}=3 \mathrm{~K}$ \\
Combustion chamber & fuel ratio $=1$ (high gas & Pump & $\eta_{\text {is }}=0.95 ; \eta_{\text {mech }}=1$ \\
& temperature) & Turbine & $\eta_{\text {is }}=0.97 ; \eta_{\text {mech }}=1$ \\
\hline
\end{tabular}

\section{Results and discussion}

Thermodynamic process data for each stream of the hybrid plant are presented in Table 5. The reported process data maintained mass balance and energy balance of the system, based on both first and second laws of thermodynamics. Also, the thermodynamic data ensured ORC net power of about $629 \mathrm{~kW}$ at nominal condition, translating to about $20 \%$ first law efficiency of the plant.

373 Table 5 - Process data for the hybrid plant

\begin{tabular}{lllll}
\hline Stream No & Working substance & Mass flow rate $(\mathrm{kg} / \mathrm{s})$ & Temperature $\left({ }^{\circ} \mathrm{C}\right)$ & Pressure $(\mathrm{bar})$ \\
\hline 1 & Thermal oil & 6.08 & 163.40 & 3 \\
2 & Thermal oil & 6.08 & 277.50 & 3 \\
3 & Thermal oil & 6.08 & 165 & 3 \\
4 & Thermal oil & 6.08 & 275 & 3 \\
5 & Thermal oil & 4.97 & 165 & 3 \\
6 & Thermal oil & 4.97 & 275 & 3 \\
7 & Air & 1.86 & 105 & 1 \\
8 & Combustion gases & 2.01 & 805.84 & 1 \\
9 & Combustion gases & 2.01 & 215 & 1 \\
10 & Thermal oil & 11.05 & 275 & 3 \\
11 & Thermal oil & 11.05 & 173.90 & 3 \\
12 & Thermal oil & 11.05 & 165 & 3 \\
13 & $M M$ & 8.55 & 204.82 & 10 \\
14 & $M M$ & 8.55 & 147.52 & 0.12 \\
15 & $M M$ & 56.62 & 0.12 \\
16 & $M M$ & 4.55 & 41.14 & 0.12 \\
17 & $M M$ & 116.92 & 10 \\
18 & $M M$ & 126.92 & 10 \\
19 & $M M$ & 25 & 10 \\
20 & Water & 8.55 & 35 & 1 \\
21 & Water & 8.55 & 20 & 1 \\
22 & Air & 50.21 & 117.31 & 1 \\
23 & Combustion gases & 2.01 & & 1 \\
\hline
\end{tabular}




\subsection{Results of conventional exergy analysis}

376 The flows of exergy in different streams and components are illustrated in Figure 2. The values in brackets represent destroyed exergy in each component. For solar field and combustion chamber, these values include exergy losses to the environment. Figure 2 is self-revealing of the components with highest and lowest destroyed exergy. For the whole system, exergetic efficiency of $10.7 \%$ was obtained. Furthermore, for comparing dissimilar components in exergy analysis of energy systems, it is established that efficiency defect and relative irreversibility are better metrics than exergy efficiency $[23,35]$. Thus, Figure 3 shows these metrics for different components of the hybrid plant. As shown, the highest efficiency defect is recorded in ORC condenser, followed by air preheater and solar field. This is due to interaction of these components with the environment. This suggests that they require adequate attention for overall system improvement. In particular, irreversibility recorded in solar field has a very high impact on the total destroyed exergy of the overall system, based on the relative irreversibility plot shown also in Figure 3. In fact, this plot shows that, although the efficiency defect in air preheater and condenser are higher than that of combustion chamber, the reverse is the case for relative irreversibility, meaning that absolute irreversibility of air preheater and condenser are quite small, after all.

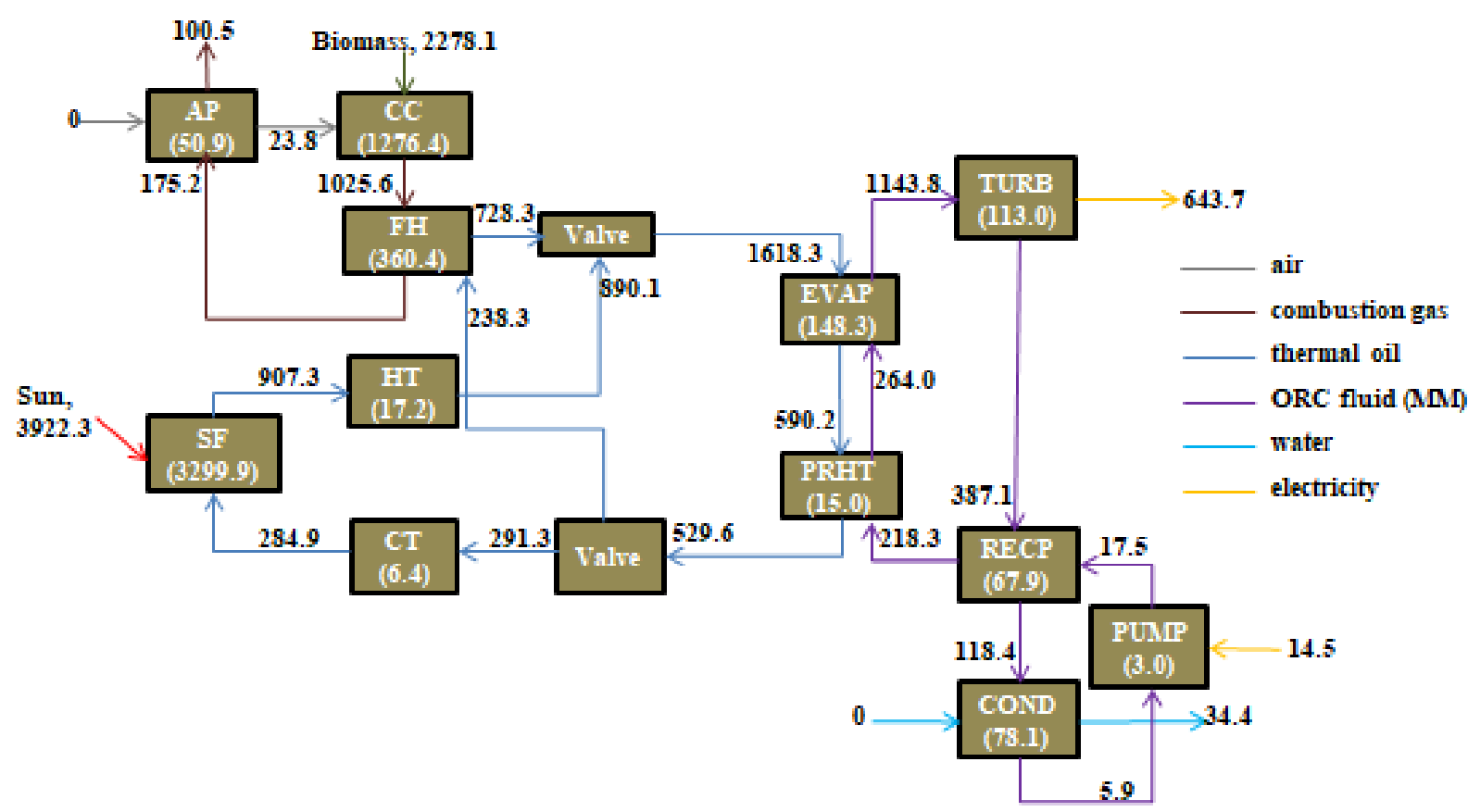

Figure 2 - Block diagram for exergy flow in the hybrid plant $(\mathrm{kW})$ 

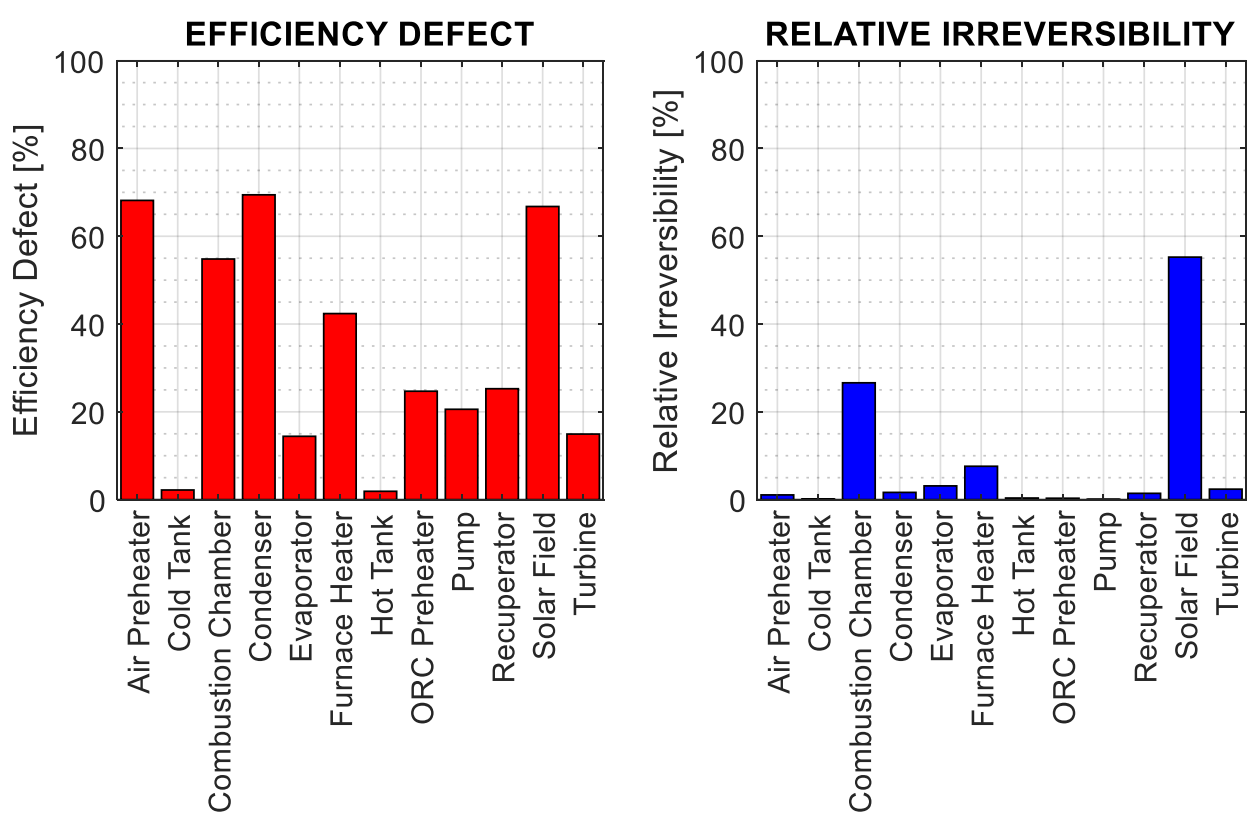

Figure 3 - Efficiency defect and relative irreversibilities of system components

\subsection{Results of exergoeconomic analysis}

\subsubsection{Conventional approach}

The flows of cost rate, $\dot{C}$ (expressed in $€ / \mathrm{h}$ ) in different streams and components are illustrated in Figure 4, for the conventional exergoeconomic approach. The values in brackets are the levelized cost rate due to investment, operation and maintenance $(\dot{Z})$ of the respective components. Here too, the figure is self-revealing of the cost implications of purchasing and operating different components of the hybrid plant. For instance, in furnace heater, the sum of cost rates of fuel streams into the component $(30.27 € / \mathrm{h}$ and $13.33 € / \mathrm{h})$ and cost rate due to investment $(1.69 € / \mathrm{h})$ is equal to the sum of cost rates of product streams emanating from the component $(40.12 € / \mathrm{h}$ and $5.17 € / \mathrm{h})$. The same analysis holds for other components. Table 6 shows the fuel and product costs of system components, as well as their performance based on conventional exergoeconomic approach. The total exergoeconomic cost rates are obtained for each component by the sum of cost rates of destroyed and lost exergy as well as investment and operation cost rates, reported in Table 6 . Exergoeconomic performance of system components is thus ranked using this sum. It is desired to be as low as possible for all components, for optimal exergoeconomic performance of the system. For components with high total cost rates, substitution with other cheaper devices with comparable exergetic performance should be considered. In this regard, system improvement requires that due attention be focused on solar field, combustion chamber, furnace heater, ORC heat exchangers and turbine, furnace heater and TES tanks, for possible replacement with cheaper components. For $f$, the values obtained for each component is a trade-off between the capital investment cost and exergetic performance of the component. High values imply that exergoeconomic cost rates is substantially due to investment cost, while low values indicate that total cost rates are due majorly to irreversibility and exergy losses. In this regard, investment costs play substantial role in exergoeconomic underperformance of solar field, TES tanks and ORC preheater. Conversely, for other components with relatively low $f$ values, the significance is that large chunk of their investment costs results in losses due to thermodynamic irreversibilities, and optimization efforts should therefore be focused on improving exergetic performance. Moreover, $r$ values in system components signify the relativity of unit product cost to unit fuel cost, and particular attention should be given to components with high $r$ as reported in Table 6. One result of interest obtained in this study is the cost of producing electrical energy by the hybrid plant, which is valued at 10.50 $\mathrm{c} € / \mathrm{kWh}$. This is cheaper than what obtains in the case of a solar-geothermal hybridization concept [8], where exergy cost of electricity was reported in the range of $15-17 \mathrm{c} € / \mathrm{kWh}$ for ORC 
polygeneration plant rated at $1.20 \mathrm{MW}$. This is obviously due to high investment cost of geothermal energy. For the overall solar-biomass system, $f$ value of $47.05 \%$ was obtained, implying that more than half of the total investment cost results in thermodynamic losses.

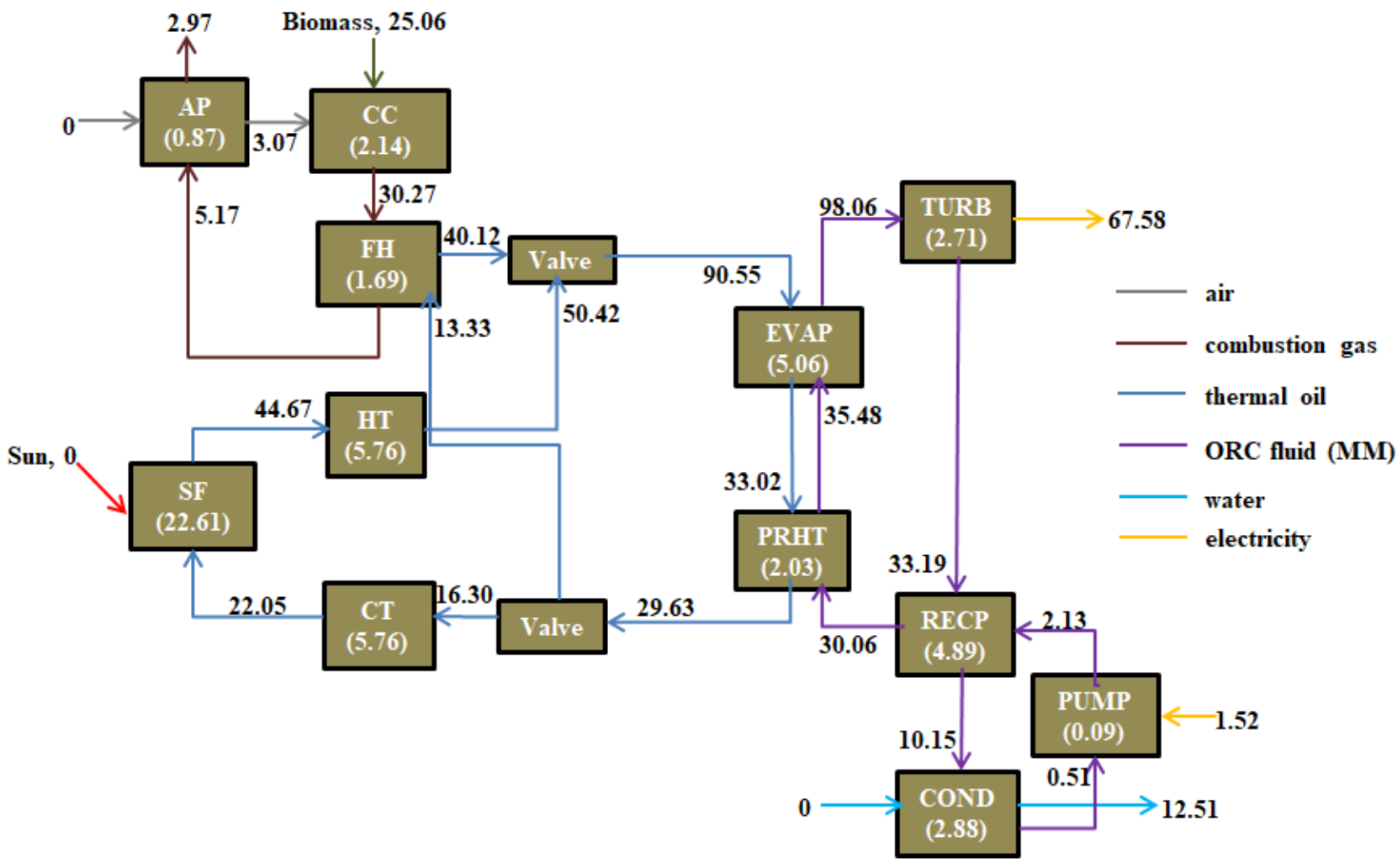

Figure 4 - Block diagram for cost rate flow in the hybrid plant for conventional approach $(€ / h)$

Table 6-Conventional exergoeconomic results for system components

\begin{tabular}{lllllllll}
\hline Component & $\begin{array}{l}\mathrm{cf}_{\mathrm{f}} \\
(€ / \mathrm{kWh})\end{array}$ & $\begin{array}{l}\mathrm{c}_{\mathrm{p}} \\
(€ / \mathrm{kWh})\end{array}$ & $\begin{array}{l}\dot{\boldsymbol{C}}_{\boldsymbol{D}} \\
(€ / \mathrm{h})\end{array}$ & $\begin{array}{l}\dot{\boldsymbol{C}}_{\boldsymbol{L}} \\
(€ / \mathrm{h})\end{array}$ & $\begin{array}{l}\dot{\boldsymbol{Z}} \\
(€ / \mathrm{h})\end{array}$ & $\begin{array}{l}\dot{\boldsymbol{Z}}+ \\
\dot{\boldsymbol{C}}_{\boldsymbol{D}}+ \\
\dot{\boldsymbol{C}}_{\boldsymbol{L}}(€ / \mathrm{h})\end{array}$ & $\begin{array}{l}\mathrm{f} \\
(\%)\end{array}$ & $\begin{array}{l}\mathrm{r} \\
(\%)\end{array}$ \\
\hline Solar field & 0 & 0.0363 & 0 & 0 & 22.62 & 22.62 & 100 & Infinity \\
Hot tank & 0.0492 & 0.0566 & 0.85 & 0 & 5.76 & 6.61 & 87.16 & 15.07 \\
Cold tank & 0.0559 & 0.0774 & 0.36 & 0 & 5.76 & 6.12 & 94.15 & 38.35 \\
Air preheater & 0.0295 & 0.1293 & 1.50 & 0 & 0.87 & 2.37 & 36.68 & 338.19 \\
Combustion & 0.0122 & 0.0295 & 15.42 & 0.18 & 2.14 & 17.74 & 12.06 & 141.52 \\
chamber & & & & & 1.69 & 12.33 & 13.70 & 85.24 \\
Furnace heater & 0.0295 & 0.0547 & 10.64 & 0 & 0.03 & 2.87 & 70.75 & 112.14 \\
ORC preheater & 0.0559 & 0.1187 & 0.84 & 0 & 2.03 & 13.36 & 37.87 & 27.13 \\
Evaporator & 0.0559 & 0.0711 & 8.30 & 0 & 5.06 & 13 & 45.66 & 62.21 \\
Recuperator & 0.0857 & 0.1391 & 5.82 & 0 & 4.89 & 10.71 & 30.05 & 324.82 \\
Condenser & 0.0857 & 0.3642 & 6.69 & 0 & 2.88 & 9.57 & 23.03 & 33.67 \\
Pump & 0.1050 & 0.1403 & 0.31 & 0 & 0.094 & 0.40 & 21.85 & 22.47 \\
Turbine & 0.0857 & 0.1050 & 9.69 & 0 & 2.71 & 12.4 & 0 & 0 \\
Valve 1 & 0.0559 & 0.0559 & 0 & 0 & 0 & 0 & 0 & 0 \\
Valve 2 & 0.0559 & 0.0559 & 0 & 0 & 0 & 0 & 0 \\
\hline
\end{tabular}

Similar to the conventional approach, flows of cost rates in different streams and components are illustrated for the integrated exergoeconomic approach, as shown in Figure 5. This is in order to show that the cost rate balance equations are equally satisfied using the integrated approach. In 
addition, when juxtaposed with Figure 4, Figure 5 reveals how the cost-rate build-up process differs in each state for conventional and integrated exergoeconomic methodologies. While the cost rate values are higher in some states for conventional approach, the reverse is the case for many other states of the hybrid plant. For instance, the cost rate of organic fluid entering turbine from evaporator exit increases by about $4 \%$ in integrated approach, relative to conventional approach, while that entering recuperator form turbine exit decreases by about $20 \%$. These cost rate variations are obviously as a result of the distinction in cost allocation to each stream based on the quality of its energy content, as implemented under the integrated approach. The cumulative effects of these variations are reflected in the unit exergy costs of products, which are electricity and warm water in this study. The difference in these product costs for the two exergoeconomic approaches could be gleaned from the cost rates of electricity and water exit stream from the condenser, based on Figures 4 and 5. However, for clearer illustration, unit exergy cost values for the two products have been plotted side by side for the two approaches, as shown in Figure 6. As can be seen, the cost of producing electricity increases from $10.50 \mathrm{c} € / \mathrm{kWh}$ in conventional approach to $12.09 \mathrm{c} € / \mathrm{kWh}$ in integrated approach, representing about $15 \%$ increase. Conversely, the cost of producing warm water decreases from $36.42 \mathrm{c} € / \mathrm{kWh}$ in conventional approach to $15.97 \mathrm{c} € / \mathrm{kWh}$ in integrated approach, representing about $56 \%$ decrease. This shows that reckoning the energy quality of each stream in allocating unit exergy costs is in compliance with the rational economic principle which suffices that market value of any product should correlate with its quality. In this regard, the exergy cost allocation process adopted in the integrated exergoeconomic approach represents a fairer distribution of component investment costs to the adjoining thermodynamic streams. Moreover, it also ensures that the cost of each product is better reflective of its utilization potentials. More specifically, credibility of the integrated exergoeconomic approach implemented in this study is apparent in the unit cost of warm water, which is more logically acceptable than what obtains following the conventional approach. In fact, relative to $36 \mathrm{c} €$ as obtained using the conventional approach, expending about $16 \mathrm{c} €$ to produce $1 \mathrm{kWh}$ of warm water at $35^{\circ} \mathrm{C}$ would certainly be more persuasive of potential investors to commit economic resources to cogeneration plant of such kind. In essence, due consideration should subsequently be given to energy quality of the different thermodynamic streams when applying SPECO approach to exergoeconomic assessment of energy systems. This is especially true in cases where waste heat is recovered in the process, for cogeneration of adjoining energy-expended products.

Furthermore, comprehensive exergoeconomic results have been computed for the integrated exergoeconomic approach, as reported in Table 7. Here too, juxtaposing Tables 6 and 7 reveals the distinctions in the main exergoeconomic results based on integrated and conventional approaches. Taking $f$ as an example, the values increase in integrated approach relative to the conventional approach, for hot tank, cold tank, ORC preheater and condenser. The effect is highest in condenser, with about $30 \%$ increase. The implication of this is that, contrary to the belief that condenser should be improved by focusing majorly on the capital cost as depicted by conventional approach, efforts should actually be made to improve its thermodynamic performance by reducing irreversibility, following the integrated approach. Conversely, with the exception of solar field whose $f$ value is the same for the two approaches, the values decrease marginally in all other components of the hybrid cogeneration plant being studied. Moreover, $f$ value of $48.6 \%$ was obtained for the overall system using integrated approach, which is more than what obtains in the conventional approach by about 1.5 percent points. This implies that the loss of investment cost is marginally lower by adopting integrated approach. 


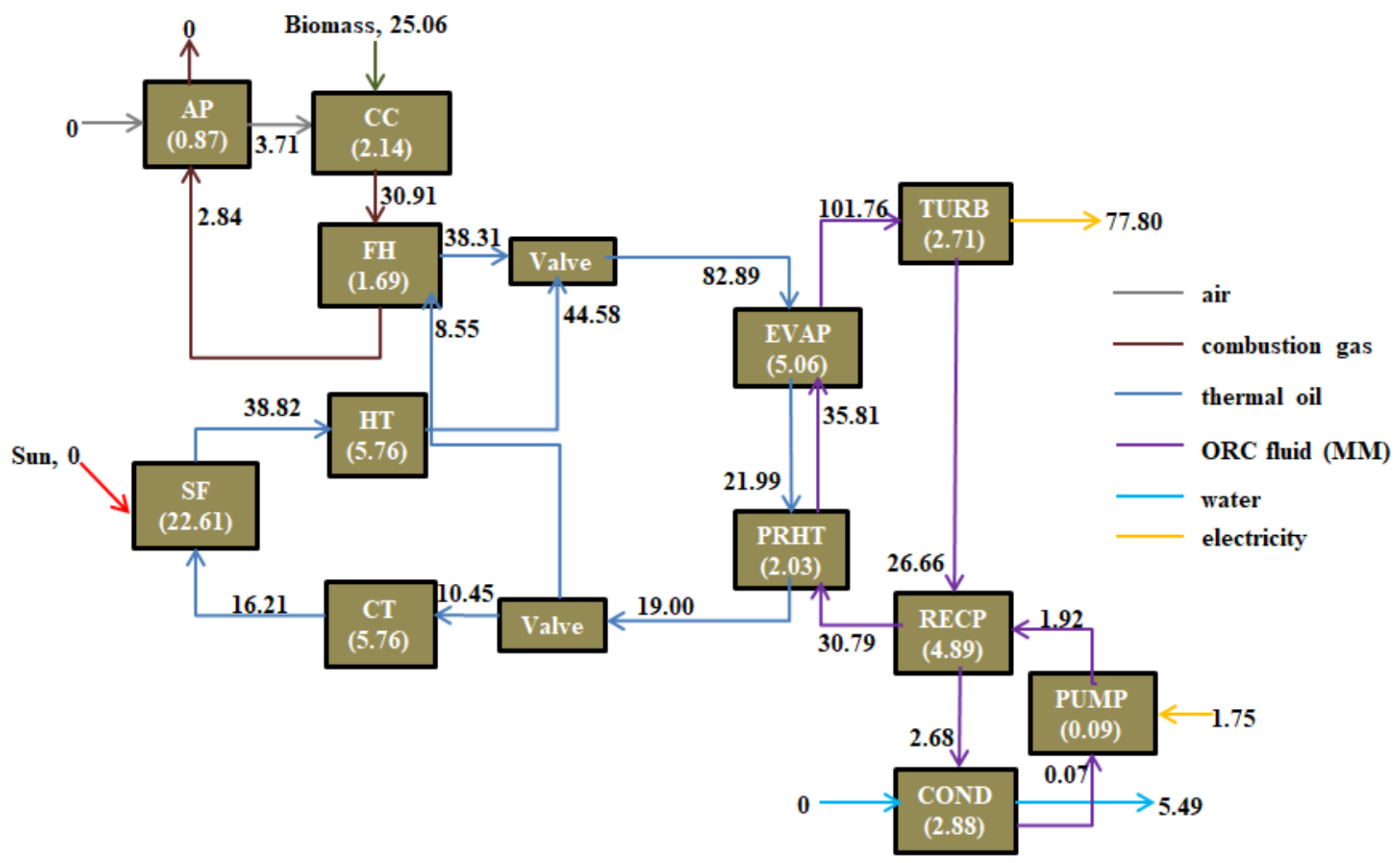

483 Figure 5 - Block diagram for cost rate flow in the hybrid plant for integrated approach $(€ / h)$ 


\begin{tabular}{lllllllll}
\hline Component & $\begin{array}{l}\mathrm{c}_{\mathrm{f}} \\
(€ / \mathrm{kWh})\end{array}$ & $\begin{array}{l}\mathrm{c}_{\mathrm{p}} \\
(€ / \mathrm{kWh})\end{array}$ & $\begin{array}{l}\dot{\boldsymbol{C}}_{\boldsymbol{D}} \\
(€ / \mathrm{h})\end{array}$ & $\begin{array}{l}\dot{\boldsymbol{C}}_{\boldsymbol{L}} \\
(€ / \mathrm{h})\end{array}$ & $\begin{array}{l}\dot{\boldsymbol{Z}} \\
(€ / \mathrm{h})\end{array}$ & $\begin{array}{l}\dot{\boldsymbol{Z}}+ \\
\dot{\boldsymbol{C}}_{\boldsymbol{D}}+\end{array}$ & $\begin{array}{l}\mathrm{f} \\
\dot{\boldsymbol{C}}_{\boldsymbol{L}}(€ / \mathrm{h})\end{array}$ & $\begin{array}{l}\mathrm{r} \\
(\%)\end{array}$ \\
\hline Solar field & 0 & 0.0363 & 0 & 0 & 22.62 & 22.62 & 100 & Infinity \\
Hot tank & 0.0428 & 0.0501 & 0.74 & 0 & 5.76 & 6.50 & 88.65 & 17.04 \\
Cold tank & 0.0359 & 0.0569 & 0.23 & 0 & 5.76 & 5.99 & 96.17 & 58.54 \\
Air preheater & 0.0380 & 0.1561 & 1.94 & 0 & 0.87 & 2.81 & 31.02 & 310.40 \\
Combustion & 0.0125 & 0.0301 & 15.77 & 0.18 & 2.14 & 18.09 & 11.82 & 141.14 \\
chamber & & & & & & & & \\
Furnace heater & 0.0330 & 0.0607 & 11.90 & 0 & 1.69 & 13.59 & 12.43 & 84.00 \\
ORC preheater & 0.0494 & 0.1100 & 0.74 & 0 & 2.03 & 2.77 & 73.27 & 122.72 \\
Evaporator & 0.0592 & 0.0750 & 8.78 & 0 & 5.06 & 13.84 & 36.55 & 26.56 \\
Recuperator & 0.0892 & 0.1437 & 6.06 & 0 & 4.89 & 10.95 & 44.67 & 61.10 \\
Condenser & 0.0232 & 0.1597 & 1.81 & 0 & 2.88 & 4.69 & 61.32 & 587.45 \\
Pump & 0.1209 & 0.1603 & 0.36 & 0 & 0.094 & 0.45 & 20.63 & 32.65 \\
Turbine & 0.0992 & 0.1209 & 11.22 & 0 & 2.71 & 13.93 & 19.45 & 21.80 \\
Valve 1 & 0.0512 & 0.0512 & 0 & 0 & 0 & 0 & 0 & 0 \\
Valve 2 & 0.0359 & 0.0559 & 0 & 0 & 0 & 0 & 0 & 0 \\
\hline
\end{tabular}

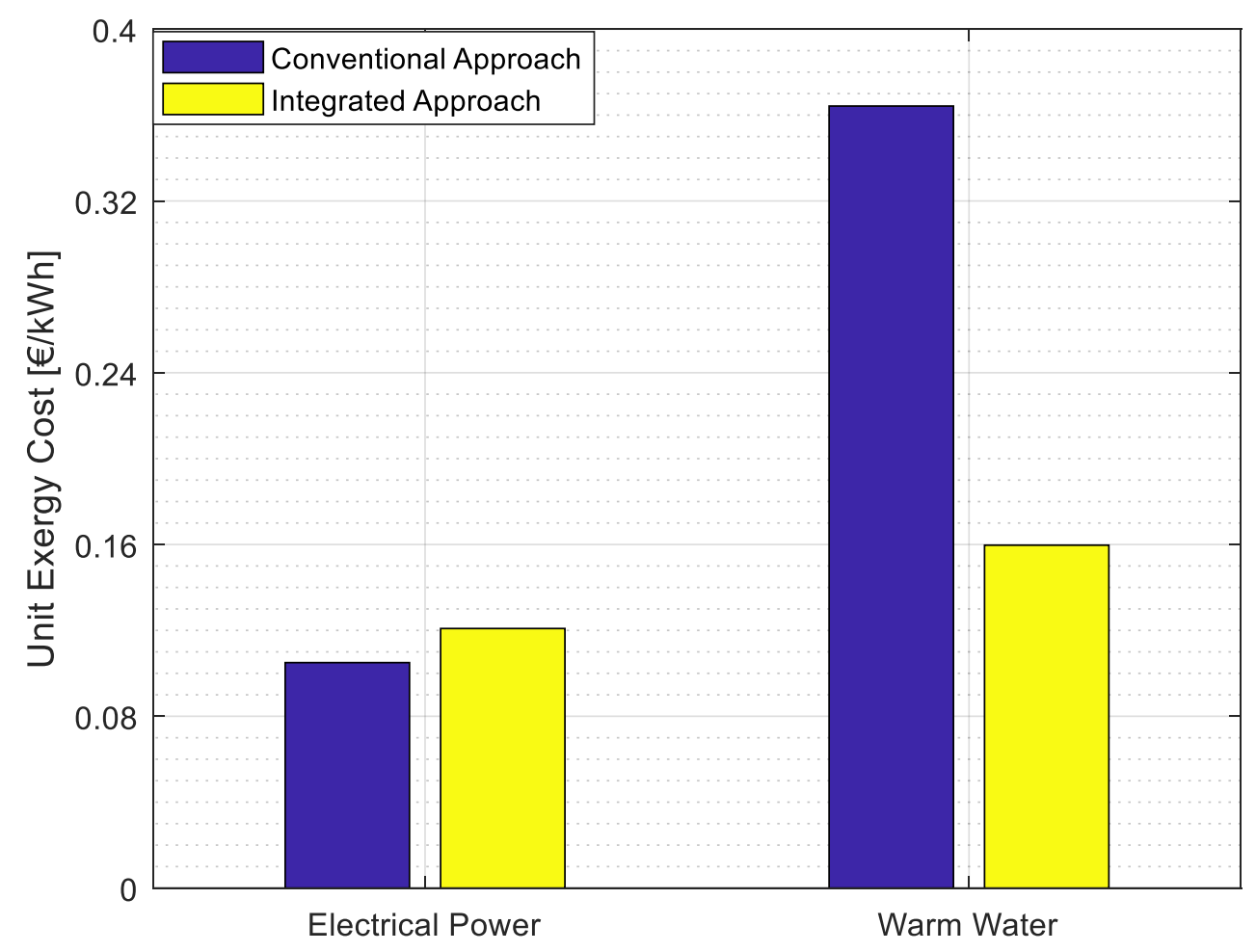

Figure 6 - Conventional and enhanced exergy efficiencies of system components

\subsection{Results of enhanced exergy analysis}

Table 8 contains the avoidable and unavoidable parts of destroyed exergy in system components, which provide a more realistic order of importance of components for system thermodynamic improvement. For instance, results of conventional exergy analysis erroneously showed that furnace heater is deserving of great optimization effort, due to its high rate of destroyed exergy. Actually, only $8.6 \%$ of this destroyed exergy is recoverable by technical optimization. In this regard, more 
improved performance of the overall system. Also, Figure 7 compares the exergetic efficiency under conventional and enhanced exergy analyses. As it would be expected, subtracting the unavoidable part of destroyed exergy from fuel exergy increases efficiency slightly, for all components.

Table 8 - Results of enhanced exergy analysis

\begin{tabular}{lllllll}
\hline Component & $\dot{\boldsymbol{E}}_{\boldsymbol{f}}(\mathrm{kW})$ & $\dot{\boldsymbol{E}}_{\boldsymbol{p}}(\mathrm{kW})$ & $\dot{\boldsymbol{E}}_{\boldsymbol{D}}(\mathrm{kW})$ & $\dot{\boldsymbol{E}}_{\text {loss }}(\mathrm{kW})$ & $\dot{\boldsymbol{E}}_{\boldsymbol{D}}^{\boldsymbol{N}}(\mathrm{kW})$ & $\dot{\boldsymbol{E}}_{\boldsymbol{D}}^{\boldsymbol{A V}}(\mathrm{kW})$ \\
\hline Solar field & 3922.3 & 622.4 & 2619.3 & 680.6 & 475.41 & 2143.89 \\
Hot tank & 907.3 & 990.1 & 17.2 & 0 & 0 & 17.22 \\
Cold tank & 291.3 & 284.8 & 6.4 & 0 & 0 & 6.39 \\
Air preheater & 74.7 & 23.8 & 50.9 & 0 & 0.44 & 50.45 \\
Combustion & 2301.9 & 1025.6 & 1261.8 & 14.6 & 269.52 & 992.24 \\
chamber & & & & & & \\
Furnace heater & 850.4 & 489.9 & 360.4 & 0 & 318.46 & 41.94 \\
ORC preheater & 60.6 & 45.6 & 15.0 & 0 & 0.64 & 14.33 \\
Evaporator & 1028.2 & 879.8 & 148.3 & 0 & 17.60 & 130.71 \\
Recuperator & 268.8 & 200.9 & 67.9 & 0 & 30.61 & 37.29 \\
Condenser & 112.4 & 34.4 & 78.1 & 0 & 19.93 & 58.13 \\
Pump & 14.5 & 11.5 & 3.0 & 0 & 0.56 & 2.42 \\
Turbine & 756.7 & 643.7 & 113.0 & 0 & 14.10 & 98.93 \\
\hline
\end{tabular}
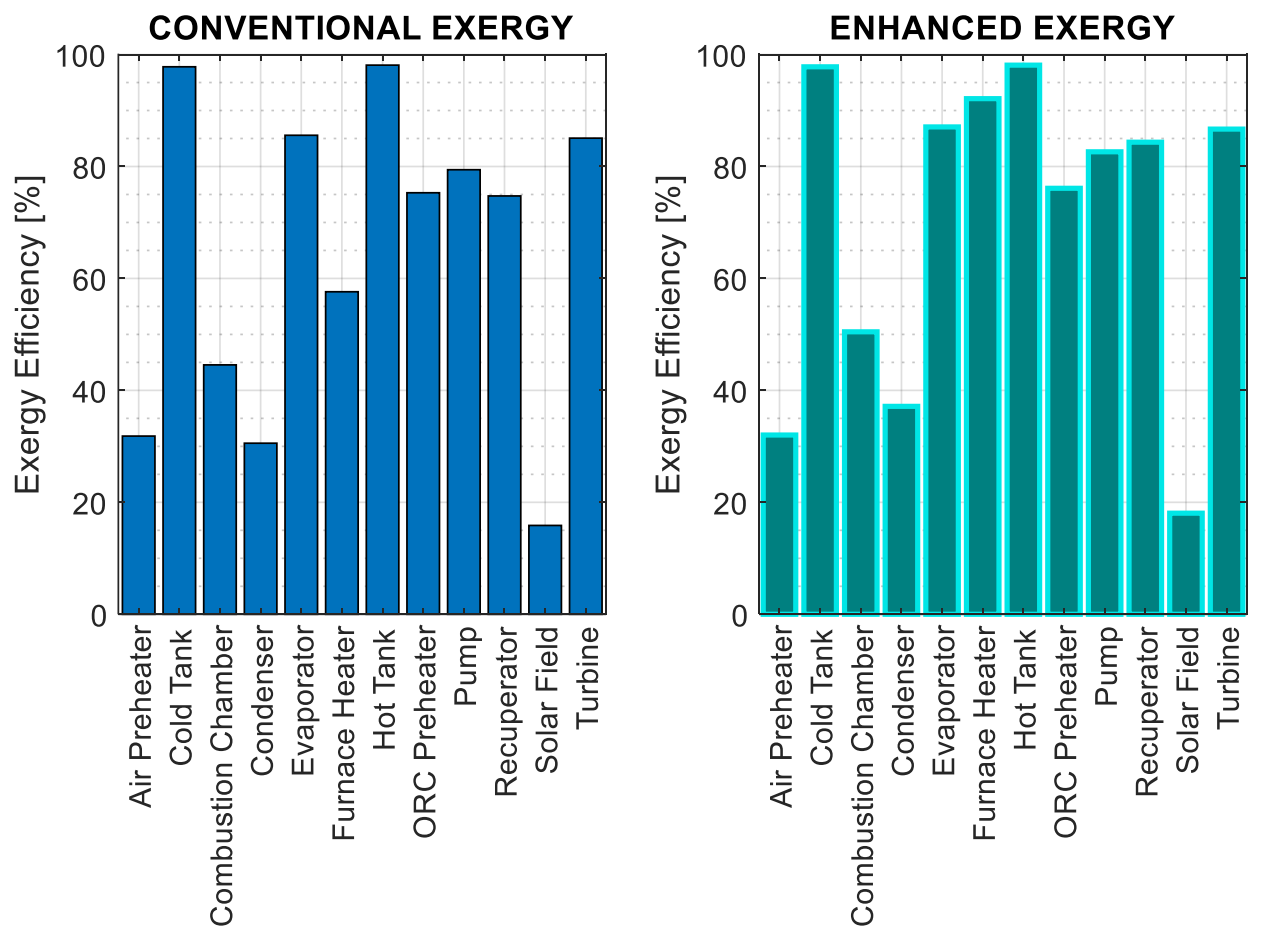

Figure 7 - Conventional and enhanced exergy efficiencies of system components

\subsubsection{Effects of DNI on solar field and system exergetic performance}

Since the solar field is directly concerned with solar irradiation, its sensitivity to change in DNI is illustrated alongside that of the system, as shown in Figure 8. As expected, the more the irradiation concentrated on the solar collectors, the higher the destroyed exergy in the solar field, and thus the less the exergetic efficiency. This trend holds also for the system, albeit with lower degree of sensitivity. Also, the deficiencies due to exergy losses decreases slightly in solar field, with 

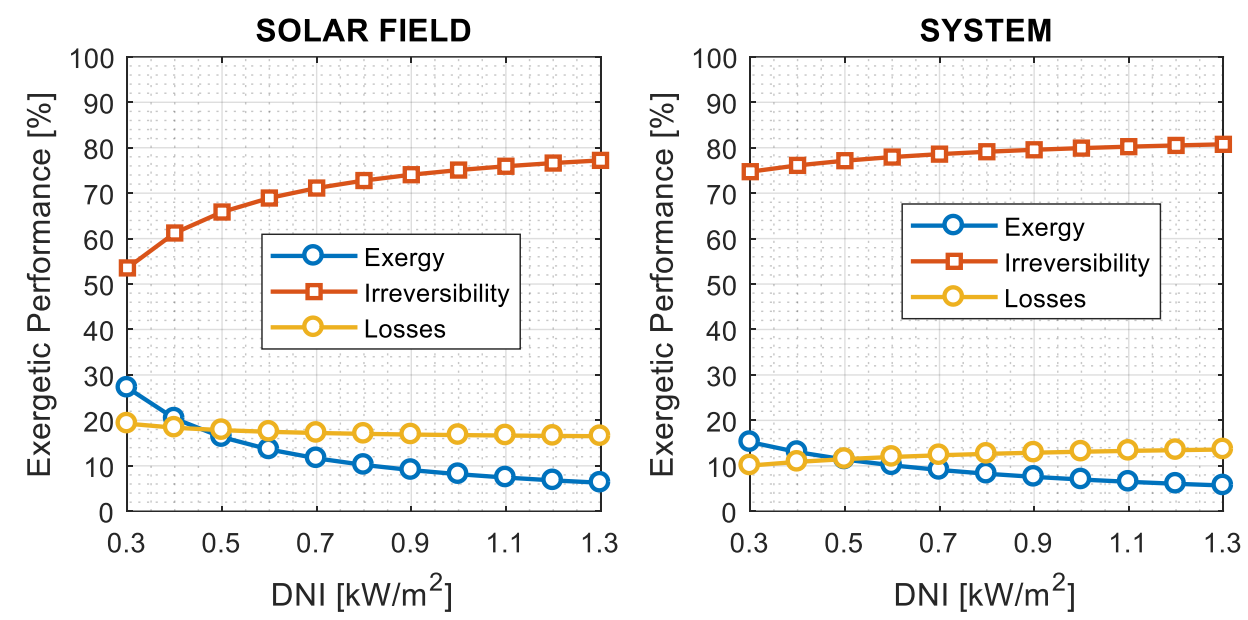

DNI $\left[\mathrm{kW} / \mathrm{m}^{2}\right]$

Figure 8 - Effects of DNI on solar field and system exergetic performance

\section{1}

512

513

514

515

516

517

518

519

520

521

522

523

\subsubsection{Effects of part load on system exergetic and exergoeconomic performance}

Variations in turbine and pump efficiencies at off-design conditions had been estimated previously, using correlations proposed by Ghasemi et al. [37]. Similar procedure had been followed for offdesign performance of heat exchangers, using correlations proposed by Manente et al. [38]. The intention here is to investigate how part load operation of the plant affects exergy and conventional exergoeconomic performance. As it can be seen in Figure 9, operating the hybrid plant at part load reduces its exergetic performance, due to slightly higher defects of irreversibility and losses. Consequently, the cost of producing electrical energy increases dramatically with decreasing inlet gross power of the hybrid plant, while the exergoeconomic factor also increases drastically, thereby keeping most of the investment cost of the system redundant. This underscores the importance of devising methods to stabilize solar systems for operation at conditions close to their design points, which is the reason behind biomass hybridization concept under investigation here.
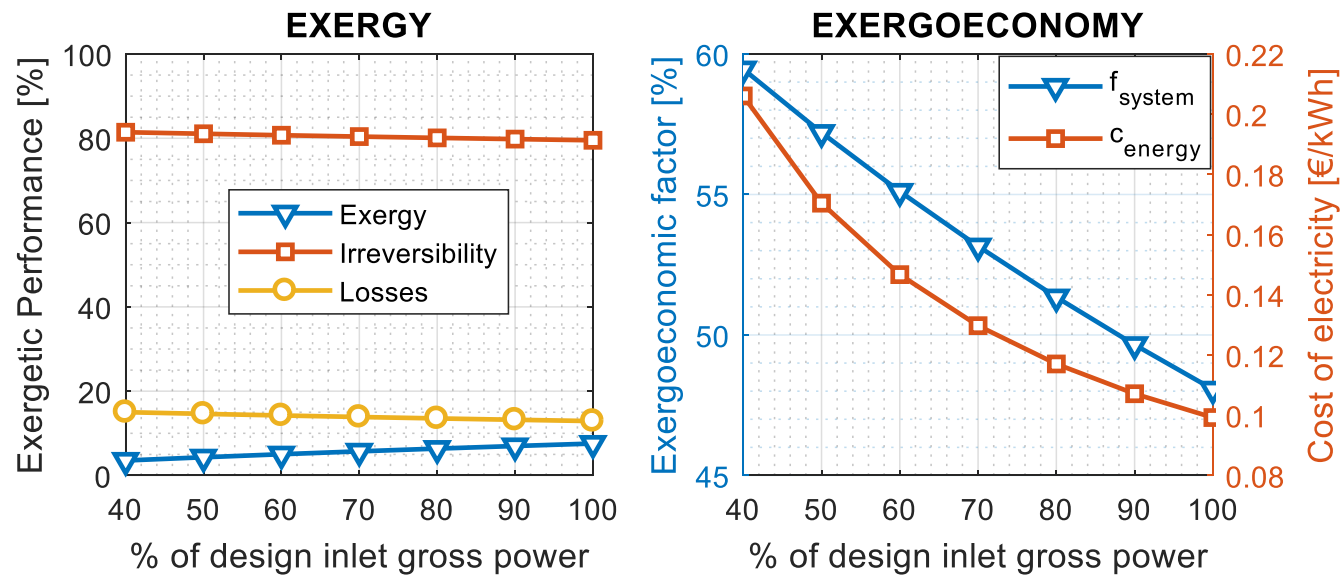

Figure 9 - Effects of part load on system exergetic and exergoeconomic performance

\section{Conclusions}

The available optimization potentials in a hybrid solar-biomass organic Rankine cycle cogeneration plant have been investigated in this paper. Thermodynamic performance of each system component was examined, using conventional and enhanced exergy analyses. Also, comprehensive economic assessment of each system component was carried out, using exergoeconomic (SPECO) methodology. As a departure from what is common in literature, energy quality of each stream was integrated into SPECO, for objective estimation of unit exergy cost of each stream, and results were compared with conventional SPECO approach. The main findings are summarised below: 
- Exergy flow rates were quantified for all thermodynamic states, and irreversibilities in different components were obtained and illustrated, using block flow diagrams. Exergetic efficiency of $10.7 \%$ was obtained for the overall hybrid plant;

- Similarly, flows of exergy cost rates were obtained and illustrated for all thermodynamic states, including investment cost rates for the components and cost rates due to irreversibility. Overall, results showed that the fully-renewable hybrid energy system studied here is capable of producing electrical energy at the rate of between 10.50 to 12.10 euro cents per $\mathrm{kWh}$, depending on the adopted exergoeconomic approach;

- The cost of producing electricity increases in integrated approach by about $15 \%$, relative to the conventional approach. Conversely, the cost of producing warm water decreases in integrated approach by about $56 \%$, which portends a more reasonable analysis for the cogeneration plant. Overall, loss of total investment cost of the hybrid plant is marginally lower by adopting integrated approach, relative to the conventional approach;

- The studied enhanced exergy analysis facilitated the decision on the components of the hybrid plant requiring utmost attention in terms of thermodynamic improvement measures, by quantifying the rate of irreversibility that could be avoided in each of the components. In this regard, thermodynamic optimization should be focused mostly on solar field, TES tanks, combustion chamber and ORC heat exchangers, amongst others. This is based on the obtained avoidable irreversibility relative to destroyed and lost exergy in each component.

Finally, it can be said that the findings in this paper will aid practical implementations in future studies when comprehensive optimization concepts are applied.

\section{Nomenclature}

\section{Letter symbols:}

$c$ average unit cost $(€ / \mathrm{kWh})$

$\dot{C} \quad$ exergy cost rate $(€ / \mathrm{h})$

$e \quad$ specific exergy $(\mathrm{kJ} / \mathrm{kg})$

$\dot{E} \quad$ rate of exergy $(\mathrm{kW})$

$\dot{E}_{S}$ exergy of the sun $(\mathrm{kW})$

$f$ exergoeconomic factor

$h$ specific enthalpy $(\mathrm{kJ} / \mathrm{kg})$

$G$ energy quality level

$H$ annual plant operation (hours)

$\dot{I}$ rate of destroyed exergy $(\mathrm{kW})$

int interest rate

$m m$ molar mass

$\dot{m}$ mass flow rate $(\mathrm{kg} / \mathrm{s})$

$M F$ maintenance factor

$N$ plant lifetime (years)

$\dot{q} \quad$ specific thermal power $\left(\mathrm{W} / \mathrm{m}^{2}\right)$

$\dot{Q}$ thermal power $(\mathrm{kW})$

$R I$ relative irreversibility

$T$ temperature $\left({ }^{\circ} \mathrm{C}, \mathrm{K}\right)$

$U$ overall heat transfer coeff. $\left(\mathrm{W} / \mathrm{m}^{2} \mathrm{~K}\right)$

$\dot{W}$ electrical power $(\mathrm{kW})$
$Z \quad$ investment cost $(€)$

$\dot{Z}$ investment and operation cost rate $(€ / h)$

\section{Greek symbols}

$\Delta T$ pinch point temperature difference $(\mathrm{K})$

$\varepsilon \quad$ exergetic (rational) efficiency

$\eta \quad$ efficiency

$\delta \quad$ efficiency defect

\section{Subscripts and superscripts}

$a$ ambient

$A$ annual

$A V$ avoidable

ch chemical

$D$ destroyed

$f$ fuel

$i$ inlet side

is isentropic

$L$ loss

mech mechanical

min minimum

$o$ outlet side

$p$ product 


$$
\begin{array}{cl}
p l & \text { pipe loss } \\
q & \text { heat } \\
w & \text { work }
\end{array}
$$

$$
\begin{aligned}
& s f \text { solar field } \\
& \text { th thermal } \\
& U N \text { unavoidable }
\end{aligned}
$$

\section{Acknowledgement}

This study was carried out under the Cooperation Agreement with "Ente Acque Sardegna" (ENAS) for the realization of the project "Thermodynamic solar plant for the development of an electrical and thermal energy smart grid" funded by P.O.R FESR 2014-2020 - Action line 4.3.1 - Framework agreement PT_CRP "Su Suercone Ambiente Identitario".

The authors thank ENAS for providing operational data and information on the Ottana Solar Facility and for setting up the experimental ORC plant.

\section{References}

[1] World Energy Outlook 2018, OECD, 2018. doi:10.1787/weo-2018-en.

[2] S. Quoilin, M. Van Den Broek, S. Declaye, P. Dewallef, V. Lemort, Techno-economic survey of organic rankine cycle (ORC) systems, Renew. Sustain. Energy Rev. 22 (2013) 168-186. doi:10.1016/j.rser.2013.01.028.

[3] J. Oyekale, F. Heberle, M. Petrollese, D. Brüggemann, G. Cau, Biomass retrofit for existing solar organic Rankine cycle power plants: Conceptual hybridization strategy and technoeconomic assessment, Energy Convers. Manag. 196 (2019) 831-845. doi:10.1016/j.enconman.2019.06.064.

[4] M. Petrollese, G. Cau, D. Cocco, The Ottana solar facility: dispatchable power from smallscale CSP plants based on ORC systems, Renew. Energy. (2018). doi:10.1016/j.renene.2018.07.013.

[5] A. Moharramian, S. Soltani, M.A. Rosen, S.M.S. Mahmoudi, M. Jafari, Conventional and enhanced thermodynamic and exergoeconomic analyses of a photovoltaic combined cycle with biomass post firing and hydrogen production, Appl. Therm. Eng. 160 (2019) 113996. doi:10.1016/J.APPLTHERMALENG.2019.113996.

[6] A. Crivellari, V. Cozzani, I. Dincer, Exergetic and exergoeconomic analyses of novel methanol synthesis processes driven by offshore renewable energies, Energy. 187 (2019) 115947. doi:10.1016/J.ENERGY.2019.115947.

[7] S. Anvari, S. Khalilarya, V. Zare, Exergoeconomic and environmental analysis of a novel configuration of solar-biomass hybrid power generation system, Energy. 165 (2018) 776789. doi:10.1016/J.ENERGY.2018.10.018.

[8] F. Calise, M.D. d'Accadia, A. Macaluso, A. Piacentino, L. Vanoli, Exergetic and exergoeconomic analysis of a novel hybrid solar-geothermal polygeneration system producing energy and water, Energy Convers. Manag. 115 (2016) 200-220. doi:10.1016/J.ENCONMAN.2016.02.029.

[9] M. Sadi, A. Arabkoohsar, Exergoeconomic analysis of a combined solar-waste driven power plant, Renew. Energy. 141 (2019) 883-893. doi:10.1016/J.RENENE.2019.04.070.

[10] E. Rahnama, M. Aghbashlo, M. Tabatabaei, M. Khanali, M.A. Rosen, Spatio-temporal solar exergoeconomic and exergoenvironmental maps for photovoltaic systems, Energy Convers. Manag. 195 (2019) 701-711. doi:10.1016/J.ENCONMAN.2019.05.051.

[11] M.M. Keshtkar, A.G. Khani, Exergoeconomic analysis and optimization of a hybrid system based on multi-objective generation system in Iran: a case study, Renew. Energy Focus. 27 (2018) 1-13. doi:10.1016/J.REF.2018.07.008.

[12] A.R.A. Elbar, M.S. Yousef, H. Hassan, Energy, exergy, exergoeconomic and 
enviroeconomic (4E) evaluation of a new integration of solar still with photovoltaic panel, J. Clean. Prod. 233 (2019) 665-680. doi:10.1016/J.JCLEPRO.2019.06.111.

[13] A. Habibollahzade, E. Houshfar, P. Ahmadi, A. Behzadi, E. Gholamian, Exergoeconomic assessment and multi-objective optimization of a solar chimney integrated with waste-toenergy, Sol. Energy. 176 (2018) 30-41. doi:10.1016/J.SOLENER.2018.10.016.

[14] A. Baghernejad, M. Yaghoubi, K. Jafarpur, Exergoeconomic comparison of three novel trigeneration systems using SOFC, biomass and solar energies, Appl. Therm. Eng. 104 (2016) 534-555. doi:10.1016/J.APPLTHERMALENG.2016.05.032.

[15] A. Lazzaretto, G. Tsatsaronis, SPECO: A systematic and general methodology for calculating efficiencies and costs in thermal systems, Energy. 31 (2006) 1257-1289. doi:10.1016/j.energy.2005.03.011.

[16] N. Edomah, Economics of Energy Supply, Ref. Modul. Earth Syst. Environ. Sci. (2018). doi:10.1016/B978-0-12-409548-9.11713-0.

[17] X.Z. Jiang, X. Wang, L. Feng, D. Zheng, L. Shi, Adapted computational method of energy level and energy quality evolution for combined cooling, heating and power systems with energy storage units, Energy. 120 (2017) 209-216. doi:10.1016/j.energy.2016.12.124.

[18] Z. Wang, W. Han, N. Zhang, M. Liu, H. Jin, Exergy cost allocation method based on energy level (ECAEL) for a CCHP system, Energy. 134 (2017) 240-247. doi:10.1016/j.energy.2017.06.015.

[19] A. Hepbasli, A key review on exergetic analysis and assessment of renewable energy resources for a sustainable future, Renew. Sustain. Energy Rev. 12 (2008) 593-661. doi:10.1016/j.rser.2006.10.001.

[20] R. Kumar, A critical review on energy, exergy, exergoeconomic and economic (4-E) analysis of thermal power plants, Eng. Sci. Technol. an Int. J. 20 (2017) 283-292. doi:10.1016/J.JESTCH.2016.08.018.

[21] G. Tsatsaronis, M.H. Park, On avoidable and unavoidable exergy destructions and investment costs in thermal systems, Energy Convers. Manag. 43 (2002) 1259-1270. doi:10.1016/S0196-8904(02)00012-2.

[22] I. Dincer, M.A. Rosen, Exergy, Elsevier Ltd, 2013.

[23] T. J. Kotas, The exergy method of thermal plant analysis, Butterworths, 1985.

[24] R. Petela, Exergy of Heat Radiation, J. Heat Transfer. 86 (2012) 187. doi:10.1115/1.3687092.

[25] G. Cau, D. Cocco, Comparison of medium-size concentrating solar power plants based on parabolic trough and linear Fresnel collectors, Energy Procedia. 45 (2014) 101-110. doi:10.1016/j.egypro.2014.01.012.

[26] P.K. Nag, Power plant engineering, Tata McGraw-Hill Publishing Company Ltd, 2008.

[27] M.E. Demir, I. Dincer, Development and analysis of a new integrated solar energy system with thermal storage for fresh water and power production, Int. J. Energy Res. 42 (2018) 2864-2874. doi:10.1002/er.3846. [28] Meteonorm: Meteonorm
https://www.meteonorm.com/en/product/productpage/meteonorm-software October 24, 2018).

[29] I.H. Bell, J. Wronski, S. Quoilin, V. Lemort, Pure and pseudo-pure fluid thermophysical property evaluation and the open-source thermophysical property library coolprop, Ind. Eng. Chem. Res. 53 (2014) 2498-2508. doi:10.1021/ie4033999.

[30] M. Thol, F.H. Dubberke, G. Rutkai, T. Windmann, A. Köster, R. Span, J. Vrabec, Fundamental equation of state correlation for hexamethyldisiloxane based on experimental and molecular simulation data, Fluid Phase Equilib. 418 (2016) 133-151. 
doi:10.1016/J.FLUID.2015.09.047.

[31] I.B. Askari, M. Ameri, F. Calise, Energy, exergy and exergo-economic analysis of different water desalination technologies powered by Linear Fresnel solar field, Desalination. 425 (2018) 37-67. doi:10.1016/j.desal.2017.10.008.

[32] R. Turton, R.C. Bailie, W.B. Whiting, J.A. Shaeiwitz, D. Bhattacharyya, Analysis, Synthesis , and Design of Chemical Processes, fourth ed, Prentice Hall, Upper Saddle River, NJ (USA), 2012.

[33] F. Heberle, M. Hofer, N. Ürlings, H. Schröder, T. Anderlohr, D. Brüggemann, Technoeconomic analysis of a solar thermal retrofit for an air-cooled geothermal Organic Rankine Cycle power plant, Renew. Energy. 113 (2017) 494-502. doi:10.1016/j.renene.2017.06.031.

[34] X. Zhang, H. Li, L. Liu, C. Bai, S. Wang, Q. Song, J. Zeng, X. Liu, G. Zhang, Exergetic and exergoeconomic assessment of a novel CHP system integrating biomass partial gasification with ground source heat pump, Energy Convers. Manag. 156 (2018) 666-679. doi:10.1016/j.enconman.2017.11.075.

[35] A. Bejan, E. Mamut, eds., Thermodynamic Optimization of Complex Energy Systems, Kluwer Academic Publishers, 1999.

[36] A. Mortazavi, M. Ameri, Conventional and advanced exergy analysis of solar flat plate air collectors, Energy. 142 (2018) 277-288. doi:10.1016/j.energy.2017.10.035.

[37] H. Ghasemi, E. Sheu, A. Tizzanini, M. Paci, A. Mitsos, Hybrid solar-geothermal power generation: Optimal retrofitting, Appl. Energy. 131 (2014) 158-170. doi:10.1016/J.APENERGY.2014.06.010.

[38] G. Manente, A. Toffolo, A. Lazzaretto, M. Paci, An Organic Rankine Cycle off-design model for the search of the optimal control strategy, Energy. 58 (2013) 97-106. doi:10.1016/j.energy.2012.12.035. 